School of Finance

University of St.Gallen

FINANCIALIZATION IN COMMODITY MARKETS:

A Passing Trend or the NeW Normal?

Zeno ADAMS

THORSTEN GLÜCK

Working PAPERS ON FinANCe No. 2014/13

SWISS INSTITUTE OF BANKING AND FINANCE (S/BF - HSG)

JUNE 2014

This Version August 2015 


\title{
Financialization in Commodity Markets: A Passing Trend or the New Normal?
}

\author{
Zeno Adams ${ }^{\ddagger}$ and Thorsten Glück ${ }^{\S}$
}

August 2015

‡ Zeno Adams, Swiss Institute of Banking and Finance, University of St.Gallen, Rosenbergstrasse 52, 9000 St. Gallen, Switzerland, Phone: +41 (0)71 224 7057, Fax: +41 (0)71 224 7088, Email: zeno.adams@unisg.ch.

$\S$ Thorsten Glück, d-fine GmbH, Opernplatz 2, 60313 Frankfurt am Main, Germany, Phone: +49 (0)69 907370, Email: info@d-fine.de. 


\title{
Financialization in Commodity Markets: A Passing Trend or the New Normal?
}

\begin{abstract}
In this paper, we show that large inflows into commodity investments, a recent phenomenon known as financialization, has changed the behavior and dependence structure between commodities and the general stock market. The common perception is that the increase in comovements is the result of distressed investors selling both assets during the 2007-2009 financial crisis. We show that financial distress alone cannot explain the size and persistence of comovements. Instead, we argue that commodities have become an investment style for institutional investors. Given that institutional investors continue to target funds into commodities, we predict spillovers between commodities and the stock market to remain high in the future.
\end{abstract}

Keywords: $\quad$ Financialization; commodities; risk spillovers; style investing; state-dependent sensitivity VaR

JEL-Classification: $\quad$ G01, G13, Q02

An earlier version of this paper circulated under the title "Financialization in Commodity Markets: Disentangling the Crisis from the Style Effect”. We would like to thank Marc Arnold, Martin Brown, John Cochrane, Péter Erdös, Roland Füss, Marcel Prokopczuk, George Skiadopoulos, Marcel Tyrell, two anonymous referees, and participants of the 2013 European Finance Annual Meeting and the ZU research seminar for valuable comments and suggestions. 


\section{Introduction}

The past decade witnessed a fundamental change in the composition of commodity futures market participants. Traditionally, the market was dominated by specialized investors who would earn a risk premium by providing insurance to short hedging commodity producers and long hedging commodity processors (Keynes, 1930; Hicks, 1939; Hirshleifer, 1988). Starting in the early 2000s, however, flows into commodity investments began to grow at an unprecedented rate and are reported to have increased from \$ 15 billion in 2003 to \$ 250 billion in 2009 (Irwin and Sanders, 2011). These vast inflows are mainly attributable to institutional investors that have historically never been engaged in commodity investments of such a large scale (Domanski and Heath, 2007). Conservative estimates show that from 2000 to 2010 the number of commodity index traders, i.e. long-only investors such as pension funds and insurance companies, more than quadrupled and the number of hedge funds more than tripled. In contrast, during the same time period, the amount of traders engaged in futures markets to hedge commodity price risk less than doubled (Cheng, Kirilenko, and Xiong, 2014).

Investment incentives of these new types of investors differ from those of traditional investors. For instance, Commodity Index Traders intensify their investment in commodities to improve portfolio diversification (Norrish, 2010) while trading decisions of hedge funds are driven by past increases in spot prices and high roll returns (Domanski and Heath, 2007). The appearance of these new types of investors had therefore important consequences for the behavior of commodities in financial markets, and the way commodities are linked to other assets. For instance, Tang and Xiong (2012) argue that these vast inflows led to a process of integration of commodity futures markets with other financial markets in which portfolio rebalancing of index investors can cause volatility spillovers from outside to commodity markets. This process, commonly referred to as the financialization of commodity markets, has been observed with concern among policy makers who made commodity index traders responsible for the unwarranted increase in energy and food prices. ${ }^{1}$ The shift in the behavior of commodities has also sparked the interest of the academic literature and marks an important change from the traditional description of commodities as an asset class that

${ }^{1}$ See for instance the U.S. Senate Permanent Subcommittee on Investigations (2009). More generally, financialization is defined as the increasing dominance of the finance industry and the expanding role of financial motives in the overall economy (Casey, 2011). 
reliably delivers returns with low correlation to the stock market (Bessembinder, 1992, Bessembinder and Chan, 1992, Gorton and Rouwenhorst, 2006). ${ }^{2}$

Previous studies note that the behavior of commodities appears to have changed somewhere between 2004 and the 2007-2009 financial crisis (Tang and Xiong, 2012; Daskalaki and Skiadopoulos, 2011). We will be more specific and use a statistical framework to determine the exact date associated with a fundamental change in the relation between commodities and stocks. While Tang and Xiong (2012) report that significant investments from commodity index traders began already in 2004, we will show that the impact of these investments did not materialize before September 2008. Identifying the break in the correlation structure will prove useful when we explore changes in commodity behavior. As a measure for this relation we use the returns correlation. However, we do not follow the existing literature to identify changes in correlation by means of a parametric model with time-varying correlations, i.e. a multivariate GARCH (Engle, Granger, and Kraft, 1984). When it comes to the implementation of these models, the researcher is confronted with a multitude of competing MGARCH specifications, each of them implying a different pattern of correlation dynamics (Kroner and Ng, 1998, Bauwens, Laurent, and Rombouts, 2006). As a consequence, the results from these models can be highly misleading (Füss, Glück, and Mutl, 2012). For this reason, we identify a change in correlation using a simple yet efficient algorithm for correlation change-point inference (Galeano and Wied, 2014). We thereby circumvent a possibly misspecified parametric model.

Identification of a structural change in the correlations between commodities and the stock market allows us to split the sample into a pre- and a post-financialization period. We quantify the impact of the structural change by estimating the transmission of a shock in the stock market to the commodity market during both periods. We thereby apply an empirical approach based on risk spillovers (Adams, Füss, and Gropp, 2014). In contrast to correlations, this approach allows us to measure the direction of the impact and, given the model is properly specified, provides a causal interpretation of the spillovers. ${ }^{3}$

${ }^{2}$ A number of studies focus on different aspects of financialization in commodity futures markets. For instance, Henderson, Pearson and Wang (2015) measure the impact of financial investors on commodity spot and futures prices using data on commodity linked notes (CLNs). They thereby circumvent a common endogeneity problem between commodity prices and investment flows. Tang and Zhu (2015) show how collateral demand for physical commodities in China increases spot and futures prices. For an excellent overview, see Irwin and Sanders (2011).

${ }^{3}$ The empirical literature on financialization in commodity markets concentrates on the implications for commodity returns rather than commodity risk. Our own experience from modeling spillovers in different ways 
We show that risk spillovers from stocks to commodities were nonexistent before 2008 but have increased significantly since then. It would seem reasonable to explain the sudden appearance of risk spillovers by the inception of the financial crisis, which had its full scale impact on markets following the weeks after the Lehman default (Bartram and Bodnar, 2009): in the months following the Lehman collapse in September 2008, the prices of most tradable assets experienced simultaneous sharp declines within the same days. A prominent model for the explanation of this phenomenon is the Brunnermeier and Pedersen (2009) liquidity and loss spiral which has been adopted by many studies investigating comovements and spillovers among asset classes and financial institutions (see, e.g., Adrian and Brunnermeier, 2011; Acharya et al., 2010; Shleifer and Vishny, 2011, and the reference therein). Cheng, Kirilenko, and Xiong (2014) show that the liquidity and loss spiral is also relevant for commodity markets: in an effort to raise liquidity, distressed financial investors were forced to unwind their long commodity positions, thereby causing a shortfall for shorthedging commodity producers. The simultaneous disposition of commodities and stocks thereby generated a pronounced spike in their correlation structure. Indeed, our empirical results show that risk spillovers from stocks to commodities reach their peak during the market distress period of 2008. However, we also make an observation that appears to stand in contrast with the notion that risk spillovers from the stock market to commodities are essentially a phenomenon of the financial crisis. Although the period of high volatility ended around July 2009, we show that spillovers remain persistently high until the end of 2013. One important finding in our paper is therefore that the risk spillovers from stocks to commodities are more persistent than what could be explained by the impact of the financial crisis alone. The financial crisis may have uncovered and even amplified the dependence structure caused by financialization, but financialization seems to have a strong influence on spillovers even without the general environment of contagion that was present during the financial crisis.

In this paper, we argue that this previously unobserved factor, which is mainly responsible for creating the transmission channel from stocks to commodities is essentially a style effect. The idea of an investment style goes back to Barberis and Shleifer (2003), who argue that investors form asset categories such as small-cap stocks, value stocks, and oil companies. This classification is useful to investors because it simplifies portfolio investment decisions and enables them to evaluate the performance of portfolio managers relative to a benchmark. The assets categories are often called "styles" and portfolio allocation based on

suggests that many important transmissions between stocks and commodities cannot be observed in returns but are only visible in some measure of risk. We discuss this issue in more detail in section 2. 
styles rather than individual securities is called "style investing”. Our hypothesis is that as commodities started to become a significant part of financial investors' portfolios, they were treated as a new category within the universe of stocks. As a consequence, commodities became part of a more general equity style. A similar view has been recently advanced by Cheng and Xiong (2013), who report that commodity index traders "treat commodity futures as an asset class just like stocks and bonds”. As investors draw funds from one asset class and invest it into another this form of allocation generates coordinated demand shocks. Style investing therefore causes comovement among assets within a style. The assets may be unrelated on a fundamental level but the comovement is real. ${ }^{4}$ Although investment styles have traditionally been associated with stocks and mutual funds rather than commodities, the concept of comovement being caused by an outside asset that becomes part of an investment style is not new. For instance, Barberis, Shleifer, and Wurgler (2005) show that the comovement between a stock and the S\&P 500 index increases when a stock is added to that Index, and Boyer (2011) finds that economically meaningless fund labels have explanatory power for the return comovements of index constituents. More recently, Wahal and Yavuz (2013) show that in the past, the regression coefficient on a style factor for stocks was not significantly different from zero but started to show explanatory power beginning in 1988, which coincides with increased use of size and value categorization in mutual funds. In short, the appearance and disappearance of investment styles is a common phenomenon in stock markets and can be driven by simple factors that are detached from economic fundamentals.

Styles are born from good economic news or following academic work documenting the superior performance of an asset group. Bad economic news about competing assets further accelerates style formation. For instance, the poor performance of value stocks in 1998-1999 is likely to have caused the large investment flows from value stocks into growth stocks, leading to the spectacular performance of growth stocks. Style formation therefore depends not on absolute but on relative attractiveness among assets. We interpret the rising popularity of commodity investments in this light. Panel A of Figure 1 shows the monthly performance of commodities relative to stocks and bonds since 1994. Following the burst of the dot-com bubble in 2000 the stock market entered a period of negative growth, with stock prices decreasing by roughly 20\% per year from 2000 to 2003. During the same time, commodity prices increased by $8.4 \%$ per year. The poor performance of the stock market thereby induced

\footnotetext{
${ }^{4}$ The literature points to a number of examples where the degree of comovement among individual assets is difficult to explain by fundamentals. For instance, Lee, Shleifer, and Thaler (1991) find high levels of comovement among closed-end mutual funds with entirely different asset portfolios.
} 
investors to redirect some funds into commodities (Caballero, Farhi, and Gourinchas, 2008). Starting in 2004, commodity prices showed growth rates of more than $14 \%$ per year. Panel B of Figure 1 shows that this growth was accompanied by an increase in non-commercial long positions for a number of popular commodity futures. ${ }^{5}$ The superior performance of commodities is likely to have recruited new investors because commodity prices and futures long positions experienced another upswing in early 2008. In other words, the large inflows turned commodity investments into a self-fulfilling success, which in turn attracts even more financial investors, resulting in even stronger comovement with stock prices. The result of this ongoing process is persistently high interconnectedness even during moderate market periods. Finally, the price crash at the end of 2008 occurred simultaneously across a number of asset classes so that the relative attractiveness of commodities appears to remain high until today.

$$
<<\text { Figure } 1 \text { about here }>>
$$

The interconnectedness between stocks and commodities can occur in the form of comovements and/or spillovers. A brief distinction will help to clarify the interpretation of the empirical results in this paper. Comovements represent simultaneous changes and often occur in response to shifts in a common factor. From an empirical point of view comovements therefore have an ambiguous causal interpretation. In contrast, spillovers occur successively which allows for a decomposition into shock originating and shock receiving assets.

Many investors operate under restrictions concerning the size of the commodity position in their portfolio. Others rebalance on a periodic basis or when portfolio weights move outside a tolerance level (Cochrane, Longstaff, and Santa-Clara, 2008). Stock price fluctuations can therefore shift the asset mix from the prescribed allocation, causing spillovers from stocks to commodities. For instance, to compensate for a decline in stock prices, investors may reduce their commodities position and invest the proceeds in stocks. A fall in stock prices therefore transmits to the commodity market by reducing commodity prices. Similarly, an increase in stock prices induces investors to sell part of their stock holdings to back their commodity position. In this paper we will use a spillover methodology. Our empirical findings suggest

\footnotetext{
${ }^{5}$ The CFTC provides futures position data in the Commitments of Traders (COT) report since 2000. The report distinguishes between commercial and non-commercial hedgers. However, the accuracy of this classification has been criticized in the literature. We therefore take the graphs in panel B with a grain of salt and interpret them in terms of a more general indicator of flows into commodity markets.
} 
that the transmission channel is unidirectional: stocks affect commodities but not the other way around. ${ }^{6}$

In order to disentangle the spillovers caused by the events of the financial crisis and the emergence of the investment style we follow an approach that is similar to the one proposed by Wahal and Yavuz (2013). They show that comovement can be generated by two factors: style investing and common shocks. The style effect is thereby identified by an event that influences style investment but does not act as a common shock. In a similar way, we will compare a set of hypothetical spillovers that would be expected if they had been generated by common shocks during the financial crisis with the actually observed spillovers to expose the impact of the style factor. ${ }^{7}$ Our empirical findings suggest that common shocks have played an important role during the financial crisis of 2007-2009, but that during the more tranquil period from 2009-2013, the majority of observed spillovers can be attributed to style investing. Our results highlight the changing role of commodity investments in the broader context of portfolio diversification and have important implications for the risk management decisions of commodity speculators and institutional investors. Finally, our findings may be relevant for the ongoing debate concerning the impact of commodity speculation on run-ups in energy and food prices.

We believe that the empirical evidence in this paper in very much in favor of a style effect. However, investment styles are difficult to measure directly and we need to consider other possible explanations for the observation that risk spillovers remain high after the crisis. For instance, Socking and Xiong (forthcoming) show how informational frictions can lead market participants to falsely interpret speculation in commodity markets as a sign of economic strength. Their model offers a convincing explanation for the economic mechanism behind the transmission of commodity price changes from the financial to the physical level. Although informational frictions do not have direct implications for the link between commodities and stocks, they have the potential to amplify the effects of block investments and portfolio rebalancing that we see as the main economic mechanism in our paper. For example, an increase in commodity prices caused by inflows from financial investors may be falsely interpreted by consumers of physical commodities as a sign of economic strength. The

\footnotetext{
${ }^{6}$ A possible interpretation of this finding is that the commodity position in many portfolios remains small relative to the stock position.

7 The literature mentions a number of such shocks during the 2007-2009 financial crisis, the most important one being margin call induced selling pressure of liquid assets such as stocks and commodities. See Brunnermeier (2008) for an excellent overview.
} 
anticipation of higher economic activity temporarily raises commodity demand from commodity consumers. This additional demand contributes to the upward trajectory in commodity prices, amplifying the momentum that induces financial investors to intensify their commodity investments. Informational frictions can therefore lead to larger commodity positions in the portfolios of financial investors and have the potential to increase the importance of block investments and portfolio rebalancing. The empirical results in our paper suggest that increased long positions are the main driver behind risk spillovers. Informational frictions can therefore amplify the risk spillovers that we observe in the data and may partly explain why spillovers remain high after the financial crisis.

Our paper is related to Tang and Xiong (2012) who provide evidence that financialization caused commodities in investable indices such as the GSCI to show larger responses to shocks during the financial crisis than similar commodities that are not in an index. However, we focus on spillover effects between commodities and the stock market, rather than the impact of financialization on the comovement within the commodity class. Furthermore, Tang and Xiong briefly touch the issue of index investors but do not further investigate their importance for explaining increased spillovers after 2009. We should note that this paper is an empirical investigation of financialization. An excellent theoretical treatment of financialization in commodity markets is Basak and Pavlova (2014). Since their model predicts many of our empirical findings, we regard their work as an important theoretical foundation for our paper. ${ }^{8}$ We will briefly revisit their model in section 4 when we investigate the fact that some but not all commodities seem to be affected by financialization.

The remainder of this paper is structured as follows. In the next section, we describe the methodology used to identify the break in the correlation structure of commodities and the stock market. We also present the methodology that allows us to quantify the impact of financialization. In section 3 we discuss our empirical results regarding the exposure of commodities to risk spillovers. In Section 4 we examine why some commodities are apparently more affected by the financialization process than others. Section 5 draws our conclusions.

8 The model of Basak and Pavlova is based on the observation that institutional investors are benchmarked relative to a commodity index. Institutional investors therefore favor commodities that do well when the index as a whole is doing well. The presence of institutional investors increases both, the level and variation of commodity prices as well as the correlation between commodities and the stock market. Our empirical evidence confirms a number of important outcomes that are predicted by their model. For instance, their model shows how high uncertainty during a financial crisis can amplify the effects of financialization, an outcome that is central to our own empirical approach. 


\section{Methodology}

This section outlines our empirical approach that we use to quantify the impact of financialization on the dependence structure between commodities and stocks. It involves the following two steps: First, we locate the time frame associated with a structural change in the correlation between the returns of stocks and commodities. The importance of this step becomes clear in the empirical part of this paper where we show that the interconnectedness between commodities and stocks shifted dramatically in September 2008. This is accomplished with the statistical procedure that we describe in the following subsection. In a second step, we show that the structural change is associated with an increase in risk spillovers. ${ }^{9}$ Our measure for risk spillovers is subject to the second subsection.

\subsection{Locating Structural Changes in Correlation}

To identify and locate the structural change in correlation we implement a simple and effective algorithm provided by Galeano and Wied (2014). This algorithm involves the following steps: Given is a sample of $T$ observations of the returns vector $\left(r_{1, t}, r_{2, t}\right)^{\prime}$. Let $\rho_{t}$ denote the true but unknown unconditional correlation between $r_{1, t}$ and $r_{2, t}$ at time $t$. The algorithm starts with testing the null hypothesis of constant correlations against the alternative hypothesis of a change-point $t^{c}$, i.e.

$$
H_{0}: \rho_{t}=\rho \quad \text { for all } t \in\{1, \ldots, T\}
$$

versus

$$
H_{1}: \exists t^{c} \in\{1, \ldots, T-1\} \quad \text { such that } \rho_{t^{c}} \neq \rho_{t^{c}+1} .
$$

This is accomplished using the model-free fluctuation-type test originally proposed by Wied, Kraemer, and Dehling (2012). The test statistic is defined as

$$
Q_{T}:=\hat{D} \max _{2 \leq t \leq T} \frac{t}{\sqrt{T}}\left|\hat{\rho}_{t}-\hat{\rho}_{T}\right|,
$$

where $\hat{\rho}_{t}$ is the sample correlation over the period 1 to $t$. The scalar coefficient $\hat{D}$ is needed to adjust for correlation breaks that appear at the beginning of the sample where $\hat{\rho}_{t}$ is more

${ }^{9}$ There is a slight inconsistency between the change-point test and the approach that we use in order to quantify financialization. The available statistical change-point methodology is based on returns, but our financialization measure is based on risk. While we find strong empirical evidence for a change-point in the correlation structure, we implicitly assume that the influencing factors that drive the return linkage also impact the risk linkage. Our analysis of time-varying risk spillovers in section 3.4 suggests that this is indeed the case. 
volatile. For the sake of brevity its description is postponed to Appendix A. Under the null hypothesis and several reasonable moment and dependency restrictions, the test statistic $Q_{T}$ is asymptotically Kolmogorov distributed (Wied, Kraemer, and Dehling, 2012, Theorem 1). ${ }^{10}$ If $Q_{T}$ stays below the upper critical value the null hypothesis of constant correlation cannot be rejected and the algorithm stops. Otherwise, $H_{0}$ is rejected and there is at least one changepoint $t^{c}$ within the sample period. The estimator for the single change-point is given by

$$
t^{c}=\underset{t}{\arg \max } \hat{D} \frac{t}{\sqrt{T}}\left|\hat{\rho}_{t}-\hat{\rho}_{T}\right| .
$$

To identify further change-points, the sample is split into the two subsamples $\left[1, \ldots, \hat{t}^{c}\right]$ and $\left[\hat{t}^{c}+1, \ldots, T\right]$. These subsamples are then both tested individually. This procedure is repeated until no further change-points are detected. Galeano and Wied (2014) show that the presence of multiple change-points can affect the test's efficiency in identifying the true number of change points. The last step of the algorithm therefore consists of a refining process in which the vector of the $n$ detected change-points $\tau=\left[\hat{t}_{1}^{c}, \ldots, \hat{t}_{n}^{c}\right]$, sorted in ascending date order $\hat{t}_{1}^{c} \leq \ldots \leq \hat{t}_{n}^{c}$, is verified in subsamples containing only a single change point. Define the first observation of the sample as $\hat{t}_{0}^{c}=0$, the last observation as $\hat{t}_{n+1}^{c}=T$, and form the subsamples $\left[\hat{t}_{i-1}^{c}+1, \ldots, \hat{t}_{i+1}^{c}\right]$ for $i=1, \ldots, n$. Each subsample starts at the first observation following the previous change-point $\hat{t}_{i-1}^{c}$, includes change point $\hat{t}_{i}^{c}$, but ends just before the next changepoint $\hat{t}_{i+1}^{c}$. These subsamples are tested individually. If the null hypothesis is not rejected the change-point contained in the subsample is removed from $\tau$. The following brief example should clarify the test procedure. To test for a break in the daily correlation between copper returns and stock returns we start with the full sample from 9/15/1994 to 9/30/2013 and find a significant change-point at $8 / 29 / 2008$. The next step is to split the data in the two subsamples [9/15/1994-8/28/2008] and [8/29/2008-9/30/2013]. We test the two subsamples individually and find another change-point in the first subsample at 6/24/1999. The test statistic in the second subsample is insignificant. The presence of the second change-point interferes with the test statistic for the first change-point that was detected using the entire sample. The last step therefore involves a refining process in which we test the subsamples [9/15/1994-8/28/2008] and [6/24/1999-9/30/2013]. The test statistics for both subsamples remains significant and

${ }^{10}$ See assumptions A.1 to A.5 in Wied, Krämer, and Dehling (2012). In particular, it is assumed that $\left\{\left(r_{1, t}, r_{2, t}\right)^{\prime}\right\}$ is near-epoch dependent. For an extensive discussion see Davidson (1994, Ch. 17). 
confirms the presence of both change-points: $\tau=[6 / 24 / 1999,8 / 29 / 2008]$. As shown in Galeano and Wied (2014), this procedure detects the correct number of correlation changepoints.

\subsection{Quantifying Risk Spillovers}

Once we have identified the structural change in correlation, we quantify and compare the size of risk spillovers from the stock market to commodities for the periods before and after the break. The change point in the previous section was detected using correlations because the available statistical methodology is designed for correlation breaks. However, we proceed in this section using risk spillovers instead of correlations. To address our main research question, it is important that we identify the direction and size of spillovers. Correlations, however, are non-directional and are therefore insufficient for our purpose.

Another issue that warrants a brief discussion is the distinction between return spillovers versus risk spillovers. We believe that measuring spillovers in risk is superior to measuring spillovers in returns for at least two reasons. First, a major drawback of investigating returns is that the largest spillovers typically occur in an environment of high uncertainty and financial distress. During this period, returns typically show an alternating pattern of large positive and negative returns as market participants struggle to process incoming information. ${ }^{11}$ In contrast, a risk based measure such as VaR does not show this alternating pattern but consistently indicates a high level of risk. As a consequence, a significant fraction of spillovers are not observable in returns and can only be detected in some form of risk. ${ }^{12}$ Second, Cheng, Kirilenko, and Xiong (2014) show that the correlation between financial investors' positions and futures returns changes over time but is zero on average. The correlation is negative during normal market periods as commercial hedgers attract investors into the market by offering futures at a discount. On the other hand, the risk bearing capacity of financial investors is limited. During episodes of financial distress investors reduce their commodity long positions at the same time as prices fall, leading to a positive correlation. In contrast, risk spillovers respond in a similar way to the economic

${ }^{11}$ If we consider the crisis years from 2007 to 2009 and focus on absolute commodity returns of more than 2 standard deviations, we observe that large negative returns on day $t$ are followed by medium or large positive returns on day $t+1$ in 32\% of all cases. Similarly, large positive returns on day $t$ are followed by medium or large negative returns on the following day $t+1$ in $53 \%$ of cases.

${ }^{12}$ Hence, we do not follow the existing literature investigating whether financial investor positions are either contemporaneously correlated with futures returns or Granger-cause futures returns (Büyükşahin, Haigh, and Robe, 2010; Büyükşahin and Harris, 2011; Irwin and Sanders, 2012; Stoll and Whaley, 2010). 
environments that produce positive and negative correlations. What matters for risk spillover is a response of one asset to shocks in another asset. The importance of shocks for the formation of risk spillovers can explain why we fail to detect spillovers during the period 2004 to the first half of 2008, which was an episode characterized by substantial commodity inflows, but observe economically and statistically large spillovers during the financial crisis, which was marked by commodity outflows: the first period from 2004 to 2008 was a tranquil episode only rarely disrupted by financial shocks. In addition, financial investor's commodity holdings, although on an upward trajectory, had probably not reached a sufficient size to generate spillovers in the absence of large shocks. In contrast, the presence of shocks during the financial crisis caused simultaneous losses across commodities and other assets, leading to risk spillovers despite some outflows from commodity investments.

The recent finance literature has proposed a number of empirical approaches to measure spillovers in risk, often with an emphasis on the tails of the risk distribution. ${ }^{13}$ We can therefore obtain economically important information from focusing on risk spillovers. The empirical approach in this paper is based on the state-dependent sensitivity value-at-risk (SDSVaR) model of Adams, Füss, and Gropp (2014). This approach is an extension of the common value-at-risk model in that it explicitly accounts for spillovers from other relevant markets. In other words, while the common VaR considers financial assets in isolation, the SDSVaR explicitly models their linkages to account for the systemic nature of risk during a crisis. We should note that very similar risk spillovers can be estimated using volatility instead of VaR. However, VaR has a direct and intuitive interpretation, a feature that is lacking with volatility despite its widespread use. ${ }^{14}$ Since VaR constitutes the main variable in this paper we believe that it should have a clear and intuitive interpretation.

Capturing the systemic part of shocks can be considered as the methodological key for adequate spillover measurement. Financial institutions have been shown to be particularly vulnerable to bad market news when a shock occurs in an environment of high volatility (see in particular Adrian and Brunnermeier, 2011 and Adams, Füss and Gropp, 2014). Similarly, we will show in the empirical section of this paper that spillovers from stock markets to

${ }^{13}$ See for instance Brownlees and Engle (2011), Acharya et al. (2010), Boyson, Stahel, and Stulz (2010), and Adrian and Brunnermeier (2011).

14 To highlight this point, $\sigma=6 \%$ shows that the square root of the average squared deviations of the returns from their mean is $6 \%$. In contrast, $V a R=-6 \%$ means that $6 \%$ will be the highest loss that will occur during this day with $95 \%$ probability, but that there is a small 5\% change that today’s loss will exceed $6 \%$. 
commodities are considerably higher when the shock receiving commodity is trading at a high volatility. $^{15}$

The SDSVaR follows a two-step process. First, we compute the daily univariate valueat-risk for all eight commodities: $\widehat{\operatorname{VaR}}_{i, t}=\hat{\mu}_{i, t}+z \hat{\sigma}_{i, t}{ }^{16}$ In the second step, $\widehat{\operatorname{VaR}}_{i, t}$ is now the dependent variable and is modeled as a function of the stock market VaR and some control variables. The vector of control variables includes the lag of the dependent variable, the VaR of the S\&P GSCI commodity index excluding the commodity that acts as the dependent variable, and the MSCI emerging market equity index. The purpose of the lag is to capture the strong autoregressive structure of the $\mathrm{VaR}$. The commodity index acts as a control variable and ensures that measured spillovers coming from the stock market are not biased by the presence of spillovers between different types of commodities. ${ }^{17}$ Finally, the emerging market equity index controls for price variation that is generated by the demand in emerging economies. ${ }^{18}$ If correctly specified, our risk spillovers can therefore be interpreted in a causal way rather than the weaker form of Granger-causality.

$$
\widehat{\operatorname{VaR}}_{i, t, \theta}=\alpha_{\theta}+\beta_{1, \theta} \widehat{\operatorname{VaR}}_{i, t-1}+\beta_{2, \theta} \widehat{\operatorname{VaR}}_{\text {stocks }, t}+\beta_{3, \theta} \widehat{\operatorname{VaR}}_{\text {Commod }, t}+\beta_{4, \theta} \widehat{\operatorname{VaR}}_{\text {Emerg.Mkt.,t }}+\varepsilon_{t} .
$$

Our main interest lies in the spillover coefficient $\beta_{2, \theta}$ which quantifies the degree to which shocks in the stock market impact the value-at-risk of commodity $i .^{19}$ The model in Equation (5) allows the dependent variable to respond differently to shocks when market uncertainty and volatility are high. Technically, this is achieved by estimating the parameters

${ }^{15}$ We also estimated the empirical results in this paper using returns but obtained mixed results. First, spillovers in returns do not respond to changes in market environments. In addition, the return coefficients do not show a consistent increase in spillovers since September 2008.

${ }^{16}$ Following the usual notation, $\hat{\mu}_{i, t}$ and $\hat{\sigma}_{i, t}$ are the mean return and standard deviation of commodity $i$. The time variation in the daily mean return $\hat{\mu}_{i, t}$ is insignificant and we set it to a constant value $\hat{\mu}_{i, t}=\hat{\mu}_{i}$ for simplicity. We estimate $\hat{\sigma}_{i, t}$ with the EGARCH model of Nelson (1991). The constant $z=-1.645$ denotes the 5\% quantile of the standard normal distribution. Additional details are provided in appendix C.

${ }^{17}$ This control variable is of particular relevance since Tang and Xiong (2012) report a noticeable increase in intercommodity spillovers since 2004.

${ }^{18}$ Because of nonsynchronicity in close-to-close returns from different time zones, Henderson, Pearson, and Wang (2015) include a one-period lead of the MSCI emerging market index in their regression specification. The inclusion of a lead has no impact on the empirical results in this paper and is omitted for simplicity.

${ }^{19}$ For the exogeneity requirement we need to assume that commodity $i$ is not sufficiently large to have a feedback effect on the overall stock market. We can back our assumption by swapping left-hand side and righthand side variables, regressing the stock market VaR on the VaR of commodity $i$. The spillover coefficients from these types of regressions are all statistically insignificant. 
in Equation (5) as a function of commodity i's value-at-risk distribution. For instance, the median of the VaR distribution measures the situation when commodity markets are in a normal state while a low quantile such as the $10 \%$ or $20 \%$ quantile represents the extreme negative values of the VaR during periods of high volatility. In contrast to OLS which measures the spillover sensitivity $\beta_{2, \theta}$ at the $\mathrm{VaR}$ average, quantile regression can be used to measure the spillover sensitivity for the median (when the volatility of commodity $i$ is trading at normal levels) and for low quantiles of the VaR distribution (when commodity $i$ is trading at a high volatility). We thereby choose the $12.5 \%$ quantile for the high volatility state and the $50 \%$ quantile for the normal market state. ${ }^{20}$ From a statistical viewpoint, the value-at-risk is often defined as the 5\%-quantile of the return distribution. However, for measuring spillover sensitivity during times of financial distress, we need low quantiles of the VaR distribution. The former step is necessary to obtain the desired risk measure, but it is the latter that introduces state-dependency into the model. Our empirical results indicate that distinguishing between both states has a large impact on the size of the spillover coefficient and therefore on the importance of market circumstances for transmitting stock market risk to commodities.

\section{Quantifying the Impact of Financialization}

\subsection{Data and Descriptive Statistics}

Our empirical results are based on daily returns and risk spillovers over the period 9/15/1994 to 09/30/2013 (4968 observations). Returns are measured as $r_{t}=\log \left(P_{t} / P_{t-1}\right) \cdot 100$ and risk is measured as the daily value-at-risk: $\widehat{V a R}_{i, t}=\hat{\mu}_{i, t}+z \hat{\sigma}_{i, t}$. We follow the convention to represent the stock market by the S\&P 500 index (Tang and Xiong, 2012), but our results are also robust to other stock market measures such as the MSCI world index. Shocks to commodity prices depend on economic activity in emerging market economies with energy and capital intensive growth. In addition, these economies are also important producers of commodities. To the extent that economic shocks spread to their national stock market, we can capture the impact on commodity price risk by including the MSCI Emerging Market Equity index. Due to the heterogeneity of commodity subsectors, defining a representative set

${ }^{20}$ Our choice of $12.5 \%$ for the low quantile is to some extent arbitrary but reflects the trade-off between obtaining estimates that are dominated by a few observations with very large weights (too far into the left tail of the distribution) and estimates that reflect only moderate risk (not far enough into the left tail of the distribution). The exact choice for the lower quantile has no material impact on our main results but we believe it should be somewhere between $5 \%$ and $20 \%$. 
of commodities is somewhat more involved (Erb and Harvey, 2006). For our study, we use S\&P Goldman Sachs Commodity Index (GSCI) excess return indices for corn and wheat (agricultural), crude oil and heating oil (energy), copper and aluminum (base metals), gold (precious metals) and cattle (livestock). ${ }^{21}$ Mou (2011) shows that the size of funds tracking the S\&P GSCI index is sufficiently large to have a significant impact on futures prices during the roll period. As a robustness test, we have therefore constructed commodity excess return indices from individual futures that roll a few days prior to the Goldman roll. These indices produce almost identical results to the ones based on S\&P GSCI indices. We will therefore resort to the widely-used S\&P GSCI indices throughout the paper. As shown in Table 1, these eight commodities are the main constituents of the respective subsector and account for a combined weight of 79 percent of the GSCI.

$<<$ Table 1 about here $>>$

The descriptive statistics for the stock market and commodity data is summarized in Table 2. The average returns shown in Panel A lie in a range that is commonly observed in stock- and commodity futures markets, e.g. positive returns for stocks and energy commodities but negative returns for agricultural products (Gorton, Hayashi, and Rouwenhorst, 2013). None of the sample means are statistically significant. We find significant first order autocorrelation coefficients for copper, corn, cattle, heating oil, and the S\&P 500 index. Although the log returns of these assets do not satisfy the martingale property, autocorrelations are at most 0.07 in absolute values and are thus economically negligible. In Panel B of Table 2 we report the sample correlation matrix of the log-returns. Correlations are all positive and statistically significant. The only exception is gold which exhibits a negative but insignificant correlation with stocks. Positive correlations across commodity returns are a stylized fact: commodities have been found to be closely related to each other within commodity subsectors (Erb and Harvey, 2006; Marshall, Nguyen, and Visaltanachoti, 2013). In contrast, the significant positive correlation between the returns of stocks and commodities is a relatively new observation and reflects the ongoing financialization process of commodity markets. Earlier studies have stressed the segmentation between stock and commodity futures markets (Dusak, 1973; Bessembinder, 1992) and crossmarket correlations have been found to be insignificant or significantly negative (Gorton and

${ }^{21}$ The GSCI sub-indices are based on the usual nearby or second nearby futures contract. The strategy of rolling futures contracts is similar to that implemented in related studies, e.g., Gorton, Hayashi, and Rouwenhorst (2013). Additional information can be obtained from the index provider's web site: http://us.spindices.com/index-family/commodities/sp-gsci. The commodity indices are from DataStream. 
Rouwenhorst, 2006). This closes the description of the data used in our main empirical analysis.

$$
<<\text { Table } 2 \text { about here }>>
$$

In section 4, we further examine the empirical observation that financialization has a substantial impact on some commodities while others seem to be largely unaffected. We show that the degree to which a commodity type responds to shocks in the stock market depends on the variation in the net long position of commodity index traders (CITs) and commodity futures liquidity. The empirical literature on financialization typically uses CIT positions from the Disagreggated Commitment of Traders (DCOT) report or the CFTC Large Trader Reporting System. However, several recent papers have emphasized the problems with measuring CIT positions with these data (Irwin and Sanders, 2012; Ederington and Lee, 2002). The main challenge arises from the positions of swap dealers. This group contains CITs who trade in financial swaps but also physical commodity swap dealers such as BP or Shell who are not commodity index trader but use swaps to hedge their crude oil exposure. ${ }^{22}$ Due to these shortcomings, we measure CIT net long positions using the CFTC's quarterly Index Investment Data (IID). This data set measures commodity positions before the internal netting by swap dealers and is currently the best measure of actual commodity index investment (Irwin and Sanders, 2012). Commodity futures liquidity is measured by open interest averaged over several traded maturities. The CIT net long positions and open interest variables are described in more detail in Appendix B.

\subsection{A Shift in Correlations}

In Table 3 we test all bivariate stock/commodity combinations for a structural change in correlations. The second column of Table 3 reports the Wied, Krämer, and Dehling (2012) statistic $Q_{T}$ as defined in Equation (3). The test statistics range from 2.245 in the case of gold to 5.621 for copper and are well above the $1 \%$ critical value of 1.63 . We thus reject the null hypothesis of constant returns correlations for all stock-commodity combinations. Cheng, Kirilenko, and Xiong (2014) note that because of higher volatility, one may find changing correlations during the period of the crisis even when the underlying correlation structure remains stable. For this reason, we repeat the test procedure on returns standardized by their

${ }^{22}$ Henderson, Pearson, and Wang (2015) circumvent this problem by using data on commodity linked notes (CLNs). The hedging trades on the pricing and determination dates of CLNs have a direct impact on commodity futures prices. Their results support the view that the presence of financial investors has economically important consequences for commodity spot and futures prices. 
EGARCH(1,1) conditional volatilities. As shown in the third column of Table 3, controlling for volatility does not qualitatively change the results. Again, the test statistics are all above the critical value at the 1 percent significance level. ${ }^{23}$

\section{$<<$ Table 3 about here $>>$}

Under the alternative hypothesis, there is at least one change-point $t^{c}$ such that $\rho_{t^{c}} \neq \rho_{t^{c}+1}$. Table 4 reports the change-points that have been identified using the algorithm of Galeano and Wied (2014) (see section 2.1). As shown in column 2, there has been a fundamental shift in correlation around September 2008: all stock-commodity combinations indicate a change-point between August 29, 2008 and October 15, 2008. These change-points are associated with a substantial increase in correlations (Table 4, column 3). No further change-points are detected after 2008. This indicates that changes in correlations are permanent and cannot be explained by temporary shocks such as fire sales of liquid risky assets during the crisis period. In the following section we show that the structural break detected in 2008 has important implications for the transmission of shocks from stocks to commodity markets.

$$
<<\text { Table } 4 \text { about here }>>
$$

\subsection{Risk Spillovers and Financialization}

The correlation change-point tests suggest a major shift in the behavior of commodities during September 2008. The single most important economic event during this month was the bankruptcy of Lehman Brothers on September, 15, 2008. Although our empirical results do not depend on the choice of an exact day during this month, we decided to split our sample into a pre-Lehman period (09/15/1994 - 09/15/2008, 3653 obs.) and a post-Lehman period (9/15/2008 - 9/30/2013, 1316 obs.). ${ }^{24}$ Table 5 shows the estimated spillover coefficients from Equation (5) together with the accompanying control variables during both time intervals. Over the 14 year period from 1994 to September 2008 shocks in the stock market did not impact risk in commodities. The spillover coefficients for the lower tail indicate that this feature even holds in times of high volatility: risk spillovers are estimated to be close to zero and economically insignificant. This remarkable resilience of

${ }^{23}$ Controlling for volatility using GARCH standardized residuals is a common approach in the applied literature (Bollerslev, 1990; Tse and Tsui, 1999)

${ }^{24}$ Although CITs started investing in commodity markets as early as 2004 (Tang and Xiong, 2012), the large inflows did not have any impact on commodity behavior until September 2008. We therefore define September 2008 as the beginning of the financialization period. 
commodity returns has been confirmed in a number of empirical papers and has earned commodities the reputation of providing diversification benefits "when they are needed most" (Gorton and Rouwenhorst, 2006). ${ }^{25}$ The control variables behave as expected: the autoregressive structure of the value-at-risk estimates leads to large and statistically significant first order lags. When significant, the composite commodity index was included to control for spillovers from other commodities. Except for crude- and heating oil which both show a moderate reaction to risk changes in the overall commodity index, spillovers between commodity types seem to be rare. From Panel A of Table 2 we can safely say that in the years before the crisis, shocks coming from the stock markets did not impact the risk in commodity markets in any economically important way.

Our conclusion changes in important ways if we look at the risk spillovers during the post-Lehman subsample. Panel B of Table 5 indicates that shocks in the stock market lead to substantial spillover to commodities, especially when the shock receiving commodity is trading at a high volatility. For instance, a 1\% increase in the VaR of the stock market leads to a $0.04 \%$ higher VaR in crude oil during normal market times. The same shock, however, leads to a response in the order of $0.14 \%$ during a highly volatile period. ${ }^{26}$ The results from the post-Lehman subsample show a very different picture. Commodities, historically praised for their diversification potential and low correlation with the stock markets no longer seem to be shielded from distress in the stock market. Indeed, it seems that with the beginning of the Lehman default, a new transmission channel has opened that transmits risk from stocks to the commodity market, in particular when commodities are trading at high volatility.

${ }^{25}$ Because our dependent variable itself is the result of an estimation problem the usual robust standard errors do not adequately reflect the additional model and parameter uncertainty incorporated in the dependent variable. The parameter covariance matrix is therefore estimated with the Markov chain marginal bootstrap of Kocherginsky, He, and Mu (2005) using 200 replicates.

${ }^{26}$ A spillover coefficient of 0.1428 may not seem particularly large, but it is important to note that this coefficient shows just the immediate response within the same day. The coefficients for lagged values are close to unity indicating a high persistence in the response. Over a few trading days, the cumulative response can therefore be a multiple of the initial coefficient. Further, note that the financial distress period is represented by the $12.5 \%$ quantile of the VaR distribution. The choice for this quantile is to some extent arbitrary. For instance, the same spillover coefficient of 0.1428 would increase to 0.1699 if we had selected the $5 \%$ quantile, and it would decrease to 0.1202 for the $20 \%$ quantile. However, the coefficient estimates do not change dramatically and the exact choice of a low quantile has no material impact on our main results. Finally, other stock market measures have only small effects. For example, the spillover coefficient for crude oil is somewhat higher at 0.1973 when shocks occur in the MSCI world equity index, and 0.1582 when shocks occur in the DJIA index. 
A common perception among market participants is that due to financialization, commodity prices are more sensitive to movements in stock prices, i.e. commodities have become generally riskier as an asset class. Our findings do not support this view. Our data shows no shift in either commodity or stock market volatility: daily annualized commodity market volatility during the years prior to the financial crisis from 9/15/1994 to 12/29/2006 was $19.81 \%$ (16.64\% for stocks). For the post-crisis period from 1/10/2010 to 9/30/2013 we find very similar values of $18.68 \%$ for commodities and $16.97 \%$ for stocks. We therefore interpret the increase in spillover coefficients as an important change in the comovement of commodity and stock markets. Commodities have not become a riskier investment per se, but their risk contribution to a mixed asset portfolio is likely to have increased.

It is noteworthy that we cannot replicate the findings in Table 5 when we use return spillovers instead of risk spillovers. For instance, return spillovers for heating oil and gold are not statistically significant after September 2008, and aluminum futures return spillovers stay roughly constant throughout the entire 19 year period from 1994 to 2013. Furthermore, return spillovers do not respond to changes in the regression quantiles. In fact, the coefficients for median spillovers are almost identical to the coefficients obtained from the tails of the return distribution.

\section{$<<$ Table 5 about here $>>$}

Table 5 also shows that the magnitude of the spillover coefficients varies strongly over commodity types. For instance, heating oil, crude oil, and copper show considerable reactions to stock market shocks while the behavior of other commodities such as wheat or aluminum seems to have remained unchanged. ${ }^{27}$ This behavior reflects the fact that commodity index traders tend to concentrate their funds on commodities with high past performance and high liquidity. We will investigate the causes and implications of this finding in more detail in section 4 .

In Figure 2 we take a closer inspection of the spillover coefficients of heating oil, copper, and crude oil to reveal another salient feature of the more recent dependence structure between stocks and certain commodities. The graphs in Figure 2 show the estimated spillover size on the $y$-axis over a range of regression quantiles on the $\mathrm{x}$-axis. We compare spillovers

${ }^{27}$ Our results do not depend on the specific indices provided by S\&P GSCI. We obtain very similar results using the Dow Jones-UBS commodity indices. For instance, we estimate spillover coefficients to be 0.1885, $0.0763,0.0648$, and 0.0173 for crude oil, heating oil, copper, and gold, respectively (the corresponding S\&P GSCI based estimates in Table 5 are 0.1428, 0.0336, 0.0602, and 0.0173). We also found that the difference in risk spillovers between the two subsamples is statistically significant in the second sample period (the financialization period). 
during the first sample period (left column of Figure 2) to the spillovers during the second sample period (right column). The striking feature of the more recent spillovers is that they are not only substantially higher than before, but that commodities are particularly exposed to shocks if the commodity is trading in a highly volatile market. This seems to be especially true for crude oil, which is substantially more vulnerable to shocks in the lower tails of its VaR distribution. This finding is in line with Cheng, Kirilenko, and Xiong (2014) who report that changes in CIT long positions are more sensitive to the VIX when the CIT is in a state of financial distress.

$<<$ Figure 2 about here $>>$

To put the spillover estimates in economic perspective we perform the following simulation: Two equally weighted portfolios consisting of the S\&P 500 stock index, and the three commodities heating oil, crude oil, and copper are formed. The portfolios are of equal size $-\$ 100$ million each — and receive the same one standard deviation shock at trading day $10 .^{28}$ In our treatment portfolio, the commodity investments respond to the shock according to the estimated spillover coefficients from Table 5. In contrast, the control portfolio is based on the historical view that a shock to the stock market does not affect the commodity investments. Figure 3 shows how the variation in portfolio returns changes as a consequence of financialization. For the treatment portfolio, we can observe that the reaction of commodities to the stock market shock leads to a substantially higher variation in portfolio returns. The high persistence in the VaR of the commodities furthermore implies a strong persistence of fluctuations.

$<<$ Figure 3 about here $>>$

This simple example suggests that some commodities may have lost their formerly praised diversification benefits and, more importantly, that adding commodities to a traditional stock market portfolio today provides substantially less loss protection than before $2008 .^{29}$

\subsection{Risk Spillovers: The Crisis and the Style Effect}

${ }^{28}$ In both cases, the shock occurs to the returns of the S\&P 500 index with the size of the shock being determined by the daily standard deviation of the returns for the period after the structural break (9/15/20089/30/2013).

${ }^{29}$ Büyükşahin et al. (2010) get similar results focusing on return correlations during extreme stock market changes. They conclude that "the commodity umbrella leaks when it rains heavily”. 
A common perception in the recent literature on risk spillovers is that the increased interrelationship among assets and financial institutions is a phenomenon of the 2007-2009 financial crisis alone. The main model providing convincing explanations for the spillover mechanism is the liquidity and loss spiral of Brunnermeier and Pedersen (2009). The argument, by which margin calls lead to selling pressure of other assets in a struggle to raise liquidity, has become widely accepted in the finance industry. Indeed, recent studies argue that this was the main driver of comovements between stocks and certain commodities during the 2007-2009 financial crisis (Büyükşahin, Haigh, and Robe, 2010; Tang and Xiong, 2012). The loss spiral argument provides an intuitive and attractive explanation for the observed change in commodity behavior during the 2007-2009 financial crisis. An important implication of that argument is that commodities are expected to revert to their pre-crisis behavior after 2009. In this section, however, we show that risk spillovers from stocks to commodities remain high throughout the period from 2008 to 2013, casting doubt on the loss spiral argument as the only explanation for risk spillovers. We argue that the unprecedented inflow of institutional investor money into commodity investments has led to a "style shift" in commodities, a permanent change in the way commodities behave in a portfolio of stocks. This style shift is likely to last until the funds invested into commodities decline to their precrisis levels. To support our claim empirically, Figure 4 shows risk spillovers from stocks to commodities in a 3 year rolling window over our entire sample period from 1997 to $2013 .{ }^{30}$ Figure 4 shows that after the identified break in September 2008, spillovers increased markedly, especially during times of high volatility. These findings support our conclusion from the static results in Table 5. There is however an important feature of risk spillovers that was not visible in Table 5: perhaps unexpectedly, risk spillovers did not decline with the end of the financial crisis. Instead, spillovers stayed high in the following years, especially during times of high volatility. ${ }^{31}$ For instance, we obtain very similar spillover estimates if we exclude the financial crisis and estimate risk spillovers over the more tranquil period from 08/31/2009 - 09/30/2013: risk spillovers for crude oil change from 0.1428 to 0.1379 , the spillovers for copper change from 0.0602 to 0.0561 , the ones for heating oil change from

${ }^{30}$ Since a foregoing 750 day observation window is necessary to compute the VaR and to obtain an estimate of the first spillover, the graphs begin in late 1996 instead of 1994.

${ }^{31}$ For the purpose of illustration, the time-varying coefficients in Figure 4 are estimated without the emerging market equity index which is often insignificant and causes a higher variation in the spillover coefficients. This noise is most likely due to high multicollinearity of more than $90 \%$ between the emerging market and the S\&P 500 stock index. 
0.0336 to 0.0271 , while the spillovers for gold stay constant at 0.0173 . This suggests that the economic impact of the spillovers also remains relevant after the crisis.

$$
<<\text { Figure } 4 \text { about here }>>
$$

One way to illustrate the argument of a permanent shift in spillover behavior is to construct a hypothetical value-at-risk series for crude oil. The hypothetical VaR follows the original series until the end of the financial crisis (8/31/2009). After this date, however, the hypothetical VaR is generated by a random variable with the same mean, variance, and degree of autocorrelation as before 2007. ${ }^{32}$ Since spillovers could not be observed prior to the financial crisis, a simulated $\mathrm{VaR}$ driven by random shocks can be used to describe a pre-crisis behavior. In other words, we try to disentangle the impact of the financial crisis and the impact of another factor that reflects the style shift. Panel A of Figure 5 shows both, the actual and the hypothetical VaR series for crude oil. Note that the deviation does not become noticeable until the VaR has recovered from the distress period at the end of 2009. If the increased linkages between stocks and crude oil are the result of a liquidity and loss spiral during the financial crisis, we would expect these linkages to disappear once markets have returned to a normal behavior. We compare the risk spillovers based on the actual data with the spillovers from the simulated VaR in Panel B. Because our estimates are based on a 750 day rolling window, the theoretical spillovers do not drop to zero immediately after August 2009 but rather decrease slowly until the sample window is dominated by random shocks. ${ }^{33}$ We can draw important conclusions from the difference of both spillover series. First, spillovers are higher than what we would expect under the assumption of a loss spiral as the only determinant. Second, and more importantly, the size of risk spillovers does not return to its pre-crisis level but remains high. This suggests that spillovers cannot be explained by the crisis alone but that a more permanent change has taken place. In fact, the comparison of actual and expected risk spillovers suggest that (i) the style effect has added to the existing impact of the financial crisis, amplifying the overall spillover size, and that (ii) the style effect has recently become the dominant driver of risk spillovers, replacing the initial crisis effect since about 2010.

${ }^{32}$ According to the NBER, the recession in the United States officially ended in June 2009. The period of high volatility in the S\&P 500 index returns and other financial time series seems to have ended sometime in mid-2009.

${ }^{33}$ We obtain similar but more erratic spillover series using a 500 or 250 observation window. To focus on the underlying trend, the spillover series in Figure 5 are smoothed with a Hodrick-Prescott filter. 
Although the spillover coefficients of the other commodities copper, gold, and heating oil are somewhat lower in 2013 compared to their peak during the crisis, there seems to be no general tendency to decline in the future. In the next section, we will investigate the fact that some commodities are more affected by stock market movements than others. Based on our empirical findings, we will argue that risk spillovers will be an ongoing issue over the next years as long as financial investors remain active participants in commodity futures markets.

$$
<<\text { Figure } 5 \text { about here }>>
$$

\section{Why Do Only Some Commodities Respond to Financialization?}

The empirical results in this paper show that financialization seems to materialize in some commodities but not in others. Crude oil and copper show a significant reaction to changes in stock market risk. Aluminum or wheat show no response. If the spillover channel from stocks to commodities is the consequence of commodity index traders we would expect those commodities with the highest investment inflows to be most sensitive to stock market risk. Our hypothesis is that CIT fund flows, measured by the CFTC's index investment data (IID), can explain the variation in risk spillovers over commodities and over time. In our regression setup below, CIT long positions will therefore be the main variable of interest. Although the index investment data constitutes a significant improvement over the commitment of traders reports that were used in empirical work until recently, the ability to accurately measure actual financial investor's net long positions may be limited. For instance, the "special call" issued to swap dealers to identify their commodity positions is currently limited to 43 of the largest companies that are known to commission staff to have significant commodity index swap business. ${ }^{34} \mathrm{~A}$ number of smaller traders over whom the CFTC commission has no authority to issue a "special call" are not included in the data. We attempt to mitigate potential data limitations in the index investment data by controlling explicitly for factors that are likely to drive the investment behavior of commodity index traders. We expect the following two variables to be important drivers of CIT behavior.

First, liquidity in commodity futures is important for passive investment vehicles such as commodity ETFs. To replicate benchmark indices, individual commodity futures need to be rolled over on a continuous basis. For low liquidity futures, frequent trading generates significant costs. Anecdotal evidence from the commodity industry suggests that passive investors tend to hold the major commodity index constituents such as crude oil and heating

${ }^{34}$ More information about the CFTC index investment data can be found in the appendix and in the explanatory notes at http://www.cftc.gov/MarketReports/IndexInvestmentData/ExplanatoryNotes/index.htm. 
oil, but not the smaller and less liquid ones like Kansas Wheat or cocoa. The resulting tracking error is usually not very large so that any price changes in a number of less liquid commodities can be born at their own risk. We will therefore add measures of liquidity as an additional explanatory variable.

Second, the past performance of individual commodity futures relative to a benchmark commodity index is important for active commodity investors such as commodity trading advisors and commodity pool operators. Basak and Pavlova (2014) point out that many CITs are likely to have an investment mandate that requires the evaluation of their performance relative to a benchmark such as the S\&P GSCI commodity index. They postulate that CITs will try to avoid performing poorly when their benchmark index is doing well and so have additional incentives to invest into commodities that have been shown to outperform the index when the index is performing well. We take a closer look at the relative performance of some commodities in Figure 6. Since the early 2000's there appear to have been two periods in which commodity markets showed a strong positive performance. One is a two-year period from October 2003 to September 2005 in which the GSCI composite index increased by 56\%, with another surge in commodity prices between November 2007 and July 2008 during which prices increased by 30\%. Figure 6 also shows the performance of crude oil, copper, and corn relative to the index during these two periods. ${ }^{35}$ During the 2003-2005 commodity price hike the prices for crude oil, heating oil, and copper increased particularly strongly. While the composite index increased by $56.8 \%$, crude oil prices increased by $99.5 \%$, heating oil prices increased by $113.7 \%$, and copper prices increased by $141.9 \%$. On the other hand, corn prices increased at the beginning of 2003 but then experienced a significant drop, leading to a negative return of $-34 \%$ over this period. If CITs used the experience from the 2003-2005 period to invest heavily in crude oil, heating oil, and copper, they would have gained from their crude oil and heating oil investment which were outperforming the index by $9.6 \%$ and $18.5 \%$, but would have underperformed on their copper investment which had a return of 15.3 percentage points below the index. We conclude from Figure 6 that in particular crude oil and heating oil, and to a lesser extent also copper and corn tend to outperform the index during periods of commodity price booms whereas other index constituents such as aluminum, cattle, and wheat systematically underperformed the index over the same period. Because CITs have incentives to channel their funds into crude oil, heating oil, and to some extent also copper, we add past relative performance as an explanatory variable.

35 The performance of heating oil follows very closely that of crude oil and is omitted from the graph to improve readability. 
To investigate the issue why some commodities have higher risk spillovers than other we therefore estimate the following fixed-effects panel regression:

$$
\begin{aligned}
\text { spillover }_{i, t, \theta}= & \mu_{i}+\beta_{1} \text { netlong }_{i, t}+\beta_{2} \text { liquidity }_{i, t}+ \\
& \beta_{3} \text { performance }_{i, t-3}+\beta_{4} \text { performance }_{i, t-4}+\varepsilon_{t}
\end{aligned}
$$

The variable netlong ${ }_{i, t}$ measures CIT net long positions of commodity $i$ at time $t$. We measure liquidity by open interest but also show results for other popular liquidity indicators such as the Amihud (2002) and Corwin and Schultz (2012) illiquidity measure. In a number of different settings, we found lags of three and four quarters to have the highest explanatory power for the variable relative performance. The dependent variable is the risk spillover coefficient from Equation (5) for commodities that have responded to shocks in the stock market (copper, crude oil, gold, and heating oil). The spillover coefficients of the other commodities are not statistically different from zero. The inclusion of these commodities therefore adds noise to the regression. To introduce time variation in the dependent variable the spillovers are estimated in a three-year rolling window that is based on daily data but rolled forward in quarterly steps resulting in quarterly spillovers from 2008Q3 to 2013Q3 (21 quarters). ${ }^{36}$ The subscript $\theta$ indicates that we run a regression for risk spillovers during normal markets, spillover $_{i, t, 0.5}$, and during highly volatile markets, spillover $_{i, t, 0.125}$.

The first column in Table 6 shows our baseline specification with liquidity measured by open interest. The net long position of commodity index traders is our main variable and is included in all specifications. Since long positions are measured in thousands of contracts, the estimated coefficient is quite small. To put the coefficient size in economic perspective we multiply the coefficient by the regressors' standard deviation. All coefficients in Table 6 thus show the response to a one standard deviation change. For instance, the coefficient for net long positions is estimated to be 0.0017 during volatile times. This coefficient is multiplied by the standard deviation of net long positions (12.88) to obtain the 0.022 that is reported in the table. Given the range of estimated risk spillovers from 0.0173 for gold to 0.1428 for crude oil, the size of the coefficient is also economically important. The same increase has a much lower impact on spillovers during normal. In the second and third column of Table 6 we replace open interest by the illiquidity measures of Amihud (2002) and Corwin and Schultz (2012). Both liquidity proxies confirm that less frequently traded commodities also have lower risk spillovers, perhaps because they are less attractive for financial investors. The

\footnotetext{
${ }^{36}$ The long three-year window reduces the noise in the risk spillover estimates and leads to a better model
} fit compared to shorter window sizes 
coefficients for CIT net long positions are robust to this specification change. The last column in Table 6 adds past relative performance to the regression. The coefficients are statistically and economically significant indicating that trend following and performance evaluation relative to a benchmark may be important drivers for CIT behavior. Interestingly, the coefficient of open interest becomes insignificant once we control for past performance. Our interpretation of this finding is that benchmark replication and trend following may be more important to commodity investors than liquidity. The coefficient of CIT net long positions remains robust to the inclusion of past performance which indicates that inflows from financial investors may be main driver behind the observed variation in spillover size.

$<<$ Table 6 about here $>>$

Some comments on the robustness of our results are in order. We estimate Eq.(6) using only those commodities that have significant risk spillovers in Eq.(5). If the spillover coefficient is statistically insignificant, the true coefficient is likely to be zero, i.e. the observed variation in spillovers is noise caused by sampling error. A contamination of the dependent variable by noise will reduce the efficiency of detecting the underlying signal. Ex ante, we should therefore expect estimates of a panel regression including all commodities to be less clear than the estimates based only on the statistically significant spillovers. An alternative approach based on Litzenberger and Ramaswamy (1979) would be to use all eight commodities in the regression but assigns varying weights to the observations according to the precision of the estimates. The results from this approach (not shown) leave the impact of CIT net long positions unchanged but render the coefficients for liquidity and past performance insignificant. Another issue is the autocorrelation in the dependent variable that is introduced by the rolling window estimation. We use Hansen and Hodrick (1980) standard errors to capture the autocorrelation rather than including lags of the dependent variable. The reason is that a lagged dependent variable in combination with autocorrelated residuals biases the coefficients towards zero (Hsiao, 2004). In order to capture unobserved commodity specific characteristics, our panel model contains individual fixed-effects. An F-test for the inclusion of time fixed-effects returns a test statistic of $1.584(10 \%$ critical value $=1.757)$. Therefore, we do not include time fixed-effects. A reviewer pointed out that the Federal Reserve's large-scale asset purchase program that was formally launched in December 2008 might have contributed to the size and persistence in risk spillovers by increasing the relative attractiveness of commodities for institutional investors. We examined this possibility by including Fed total assets as an additional regressor but the coefficient was statistically and economically insignificant. Finally, several authors have emphasized the importance of the 
roll return from a long position in commodity futures (e.g. Erb and Harvey, 2006; Domanski and Heath, 2007). We added the roll return in different specifications to Eq.(6) but could not find a significant effect. One reason could be that most commodities were in contango during the estimation period 2008Q3 to 2013Q3.

The findings in Table 6 are in line with our hypothesis that risk spillovers from stocks to commodity markets were not solely driven by the aftermath of the global financial crisis but that the increased participation of financial traders in commodity markets play a major role in explaining the persistently high spillovers. Recent findings in the literature on style shifts (Wahal and Yavuz, 2013; Boyer, 2011; Barberis, Shleifer, and Wurgler, 2005) suggest that something very similar might have taken place in commodity markets, i.e. commodity investments have become an investment style for stock investors. A direct testable implication of an investment style is that the inclusion of commodities to an equity style should lead to comovements between commodities and stocks, a second implication that follows directly from the first is that increased inflows of funds into commodity investments should also lead to higher spillovers. In this paper, we test both implications and find empirical evidence that supports the investment style hypothesis. Our results cannot definitely reject other stock market or commodity market specific explanations for the increases in spillovers. On the one hand, the underlying fundamental determinants that govern the comovement of stocks and commodities are unobserved and may have changed since 2008. Out investment style argument assumes that this is not the case. On the other hand, the unusual persistence in spillovers could be simply due to extended investor nervousness that has sometimes occurred after a financial crisis (Gulko, 2012, Feldstein, 1999). However, such an explanation would not explain why CIT net long positions constitute important determinants of spillover size. ${ }^{37}$

\section{Conclusion}

Over the last decade, institutional investors strongly increased their participation in commodity futures markets. The dominant presence of these new types of investors started a continuing process of financialization in which the behavior of commodities has changed in important ways. A growing literature is investigating the focal issues of this process: the puzzling synchronized price increase across many commodities during 2007 and 2008, the appearance of links between economically unrelated commodities, and the transmission of outside shocks to commodity markets. In this paper, we focus on the transmission of stock

${ }^{37}$ We can use the CBOE volatility index as a measure of investor nervousness in Eq.(6). The coefficient on the VIX is insignificant in contemporaneous and lagged form. 
market shocks to commodity markets. We make use of recent methodological advancements for detecting change-points in a correlation structure and identify a shift in the dependence structure between commodities and the stock market in 2008. In line with other studies on financialization in commodity markets (e.g., Cheng, Kirilenko, and Xiong, 2014) we find that stock market shocks did not transmit to commodity markets prior to the financial crisis, but that substantial risk spillovers occurred after September 2008. Economic theory predicts that spillovers caused by financialization should be particularly relevant in markets of high volatility (Basak and Pavlova, 2014). We find empirical evidence that this is the case: if uncertainty among investors causes a commodity to trade at a high volatility this commodity shows an increased exposure to risk spillovers from stock market shocks.

Commodities started to attract the attention of financial investors as early as 2004, but a fundamental change in the behavior of commodities did not take place before September 2008. A common perception is therefore that risk spillovers to commodities are essentially a result of the 2007-2009 financial crisis, a side effect of a more general increase in linkages among financial institutions. Our empirical results suggest that the financial crisis may have initiated and amplified the occurrence of risk spillovers, but that a second factor, which we argue could be a style effect, has replaced the crisis effect. This style effect reflects the investment behavior of commodity index traders who tend to sell stocks and commodities simultaneously or in quick succession as a reaction to changes in their portfolio values. Thus, the problem of risk spillovers is not confined to the years of the financial crisis but continues to affect portfolio risk until today. Our results therefore have important implications for the hedging performance of commodity producers, investment strategies of speculators, and, more generally, for the ongoing discussion whether financial speculation can affect commodity prices.

A natural question that arises from our analysis is whether the shift in risk spillovers is permanent or whether commodity prices will return to their pre-crisis behavior. The literature on style investing finds that when style investors move prices away from fundamental values, they generate reversals in the long run (Jegadeesh and Titman, 1993; Barberis and Shleifer, 2003). Our empirical results indicate that a reversal should only be expected if commodity index traders reverse their active role in commodity futures markets. 


\section{Appendix A: The Scalar $\hat{D}$ for the test statistic of Wied, Kraemer and Dehling (2012)}

We briefly describe the construction of the scalar $\hat{D}$ which is part of the expression in Eq.(3). For a general and in-depth treatment we refer to Wied, Krämer, and Dehling (2012, Appendix A.1). Let $\left\{\left(x_{1, t}, x_{2, t}\right)^{\prime}\right\}$ be the bivariate time-series with $E\left(\left(x_{1, t}, x_{2, t}\right)^{\prime}\right)=0$. Given is a sample of size $T$. For $i=1,2$, denote $\overline{x_{i}}=T^{-1} \sum_{t=1}^{T} x_{i, t}, \quad \overline{x_{i}^{2}}=T^{-1} \sum_{t=1}^{T} x_{i, t}^{2} \quad$ and $\hat{\sigma}_{x_{i}}=\sqrt{\overline{x_{i}^{2}}-{\overline{x_{i}}}^{2}}$. Further, denote $\overline{x_{1} x_{2}}=T^{-1} \sum_{t=1}^{T} x_{1, t} x_{2, t}$ and $\hat{\sigma}_{x_{1} x_{2}}=\overline{x_{1} x_{2}}-\overline{x_{1}} \cdot \overline{x_{2}}$. Let $k(\cdot)$ be the Bartlett kernel function. The scalar $\hat{D}$ is then given by

$$
\hat{D}=\sqrt{\hat{D}_{3} \hat{D}_{2} \hat{D}_{1} \hat{D}_{2}^{\prime} \hat{D}_{3}^{\prime}} \text {, }
$$

where

$$
\hat{D}_{1}=\sum_{t=1}^{T} \sum_{u=1}^{T} k\left(\frac{t-u}{\lfloor\log T\rfloor}\right) V_{t} V_{u}^{\prime}
$$

with $V_{t}=T^{-1 / 2}\left(x_{1, t}^{2}-\overline{x_{1}^{2}}, x_{2, t}^{2}-\overline{x_{2}^{2}}, x_{1, t}-\overline{x_{1}}, x_{2, t}-\overline{x_{2}}, x_{1, t} x_{2, t}-\overline{x_{1} x_{2}}\right)^{\prime}$,

$$
\hat{D}_{2}=\left(\begin{array}{ccccc}
1 & 0 & -2 \overline{x_{1}} & 0 & 0 \\
0 & 1 & 0 & -2 \overline{x_{1}} & 0 \\
0 & 0 & -\overline{x_{2}} & -\overline{x_{1}} & 1
\end{array}\right) \text {, }
$$

and

$$
\hat{D}_{3}=\left(-\frac{1}{2} \frac{\hat{\sigma}_{x_{1} x_{2}}}{\hat{\sigma}_{x_{2}}} \hat{\sigma}_{x_{1}}^{-3}-\frac{1}{2} \frac{\hat{\sigma}_{x_{1} x_{2}}}{\hat{\sigma}_{x_{1}}} \hat{\sigma}_{x_{2}}^{-3} \frac{1}{\hat{\sigma}_{x_{1} x_{2}}}\right) \text {. }
$$

The purpose of the scalar $\hat{D}$ is to appropriately rescale the cumulated sum of empirical correlation coefficients in such a way that convergence of $Q_{T}$ to the asymptotic null distribution is achieved. 


\section{Appendix B: Net Long Positions and Liquidity Data}

This appendix describes the two variables "net long positions" and "open interest" that are used to explain the variation in spillovers over time and across commodity sectors. The findings of these estimations were reported in Table 6. Measuring net long positions is a challenging task and generally suffers from the classification of the swap dealer position which contains financial traders but also physical commodity swap dealers that are not CITs. In this study, we measure net long positions using the Index Investment Data (IID) provided by the CFTC. The CFTC started to publish the index investment data in September 2008 in quarterly frequency, and since June 2010 on a monthly basis. Data is collected on all U.S. exchanges with more than $\$ 500$ million of reported net notional value in any one month. The notable feature of the index investment data is the "special call" issued by the CFTC to 43 financial institutions and commodity firms that were known to the commission staff to have significant commodity index swap business. These entities include index funds, swap dealers, pension funds, hedge funds, and mutual funds. Under the special call firms need to provide the gross long, gross short, and net notional values of their commodity index positions and the equivalent number of futures contracts, whether they act on their own behalf or on behalf of a client. For index investment data, the CFTC collects the entire "book of business" in futures and OTC markets. This additional data contains the information of the actual commodity positions and not just the netted amount that is ultimately managed in the futures market (Irwin and Sanders, 2012). The Index Investment Data is cross-checked by comparing it to the positions reported in the CFTC's large trader reporting system (Sanders and Irwin, 2013). According to CFTC (2010) “The index investment data represents the Commission's best effort to provide a one-day snapshot of the positions of swap dealers and index funds". ${ }^{38}$ The IID data still suffers from a number of drawbacks. For instance, a number of smaller traders over whom the CFTC commission has no authority to issue a special call are not included in the data. More importantly, the data does not allow us to disentangle the inflows of hedge funds from those of other speculators. Recent empirical work suggests that hedge funds play an important role in the transmission of shocks from stock markets to commodities (Büyükşahin and Robe, 2014).

Figure B1 shows the quarterly net long positions of index investors (left y-axis) together with the spillover coefficients (right y-axis) for the period 2008Q1 to 2013Q3. Although the graphs cannot imply causation they show that changes in net long positions tend to go together with changes in the spillover coefficient.

${ }^{38}$ Although a large part of commodity swaps and options trading is done over the counter, swap dealers themselves hedge their positions in the futures markets (Domanski and Heath, 2007; Büyükşahin et al., 2008). 

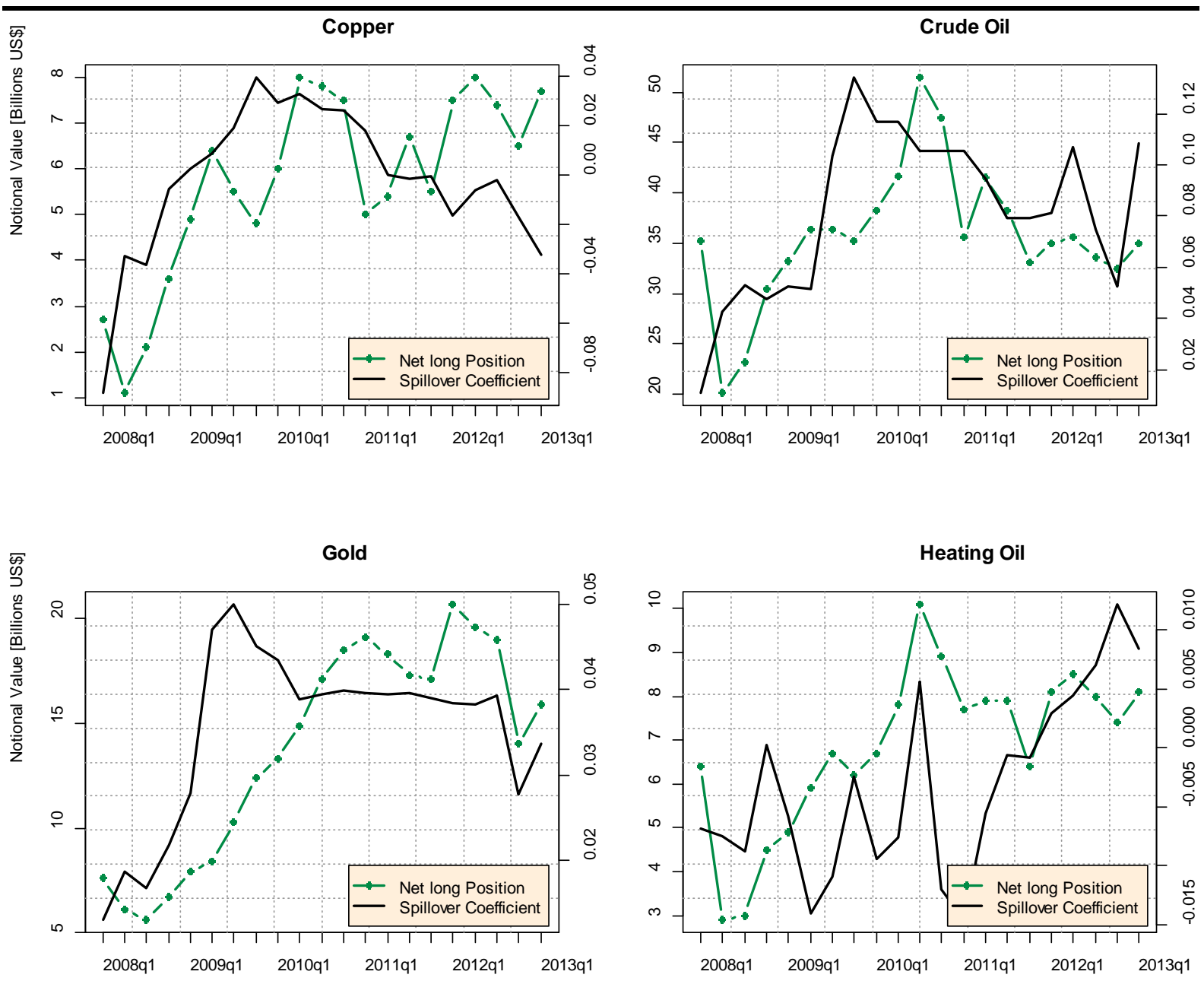

The second variable that needs additional explanation is our measure of liquidity. We measure liquidity by open interest in the futures market. Although our results also hold for other measures such as the Amihud (2002) and the Corwin and Schultz (2012) illiquidity measures, commodity market open interest may be preferred because of its ability to predict commodity returns (Hong and Yogo, 2012). Since the front-month futures may not always be the most liquid one we take the average open interest over the front-month and the next 12 contract months. Table B1 shows the exchange from which we collected the information on open interest for each commodity category. ${ }^{39}$ The data was downloaded via Quandl. Table B1 shows the corresponding Mnemonics.

${ }^{39}$ Energy futures traded on NYMEX are among the most liquidly traded commodity futures. Similarly, COMEX is a major exchange for trading gold and copper futures (see e.g. http://www.cmegroup.com/trading/metals/copper-futures-and-options-fact-card.html) 
Table B1: Data Source for the Variable Open Interest

\begin{tabular}{ccccc}
\hline & Crude Oil & Copper & Gold & Heating Oil \\
\hline Exchange & NYMEX & COMEX & COMEX & NYMEX \\
Quandl Code & OFDP/FUTURE_CL & OFDP/FUTURE_HG & OFDP/FUTURE_GC & OFDP/FUTURE_HO \\
\hline
\end{tabular}

Figure B2 shows open interest on the left y-axis and the corresponding spillover coefficients on the right y-axis for the period 2008Q1 to 2013Q3. The comovement with estimated risk spillovers does not seem to be as strong as in the case of net-long positions. However, we can observe that spillovers tend to be high during times of high liquidity.

Figure B2: Open Interest for Selected Commodities
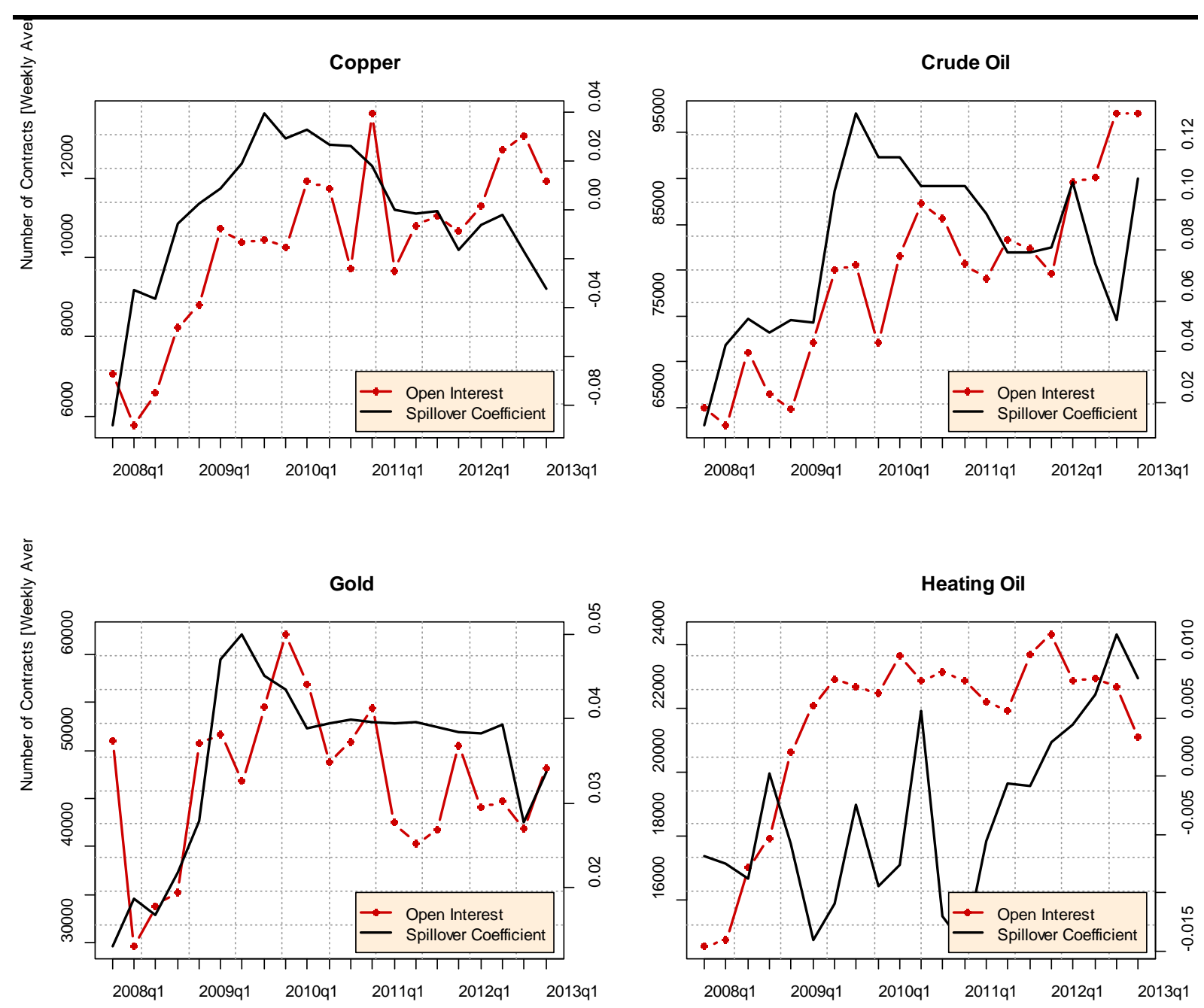


\section{Appendix C: Estimation of the Daily Univariate Value-at-Risk Measure}

In this paper, we use a simple way to estimate the daily univariate value-at-risk (Jorion, 2006): $\widehat{\operatorname{VaR}}_{i, t}=\hat{\mu}_{i, t}+z \hat{\sigma}_{i, t}$ where $\hat{\mu}_{i, t}$ is the average return of commodity $i$ at time $t, \mathrm{z}$ is the $5 \%$-quantile of the standard normal distribution (-1.645), and $\hat{\sigma}_{i, t}$ is the volatility of commodity $i$ at time $t$. Since the average daily return shows little variation over time and is close to zero it is common to set $\hat{\mu}_{i, t}=0$ or $\hat{\mu}_{i, t}=c$ for some constant c. Here we use a constant mean. As a consequence, the daily variation in the $\mathrm{VaR}$ is driven entirely by the estimated volatility $\hat{\sigma}_{i, t}$. However, using VaR instead of $\hat{\sigma}_{i, t}$ comes with the benefit of having a risk estimate with a direct and simple interpretation. We estimate $\hat{\sigma}_{i, t}$ using the asymmetric EGARCH model of Nelson (1991):

$$
\ln \left(\sigma_{i, t}^{2}\right)=\omega+\alpha\left|\frac{\varepsilon_{i, t-1}}{\sigma_{i, t-1}}\right|+\gamma \frac{\varepsilon_{i, t-1}}{\sigma_{i, t-1}}+\beta \ln \left(\sigma_{i, t-1}^{2}\right)
$$

The parameters $\alpha$ and $\gamma$ capture a potential asymmetry in the response of the volatility to positive and negative return changes. To relax the model assumption of normally distributed standardized commodity returns $r_{s}=\left(r_{i, t}-\bar{r}_{t}\right) / \sigma_{i, t}$ we assume a conditional $t$ distribution with the degrees-of-freedom parameter $v$ being estimated from the data. Accordingly, log likelihood function does not have the familiar Gaussian form but is described by

$$
\ln \mathcal{L}=-\frac{n}{2} \ln \left(\frac{\pi(v-2) \Gamma(v / 2)^{2}}{\Gamma((v+1) / 2)^{2}} \sigma_{i, t}^{2}\right)-\sum_{t=1}^{T} \frac{(v+1)}{2} \ln \left(1+\frac{\left(r_{i, t}-\bar{r}_{i}\right)^{2}}{\sigma_{i, t}^{2}(v-2)}\right)
$$




\section{References}

Acharya, V.V., L.H. Pedersen, T. Philippon, and M. Richardson (2010), “Measuring Systemic Risk”, FRB of Cleveland Working paper No. 10-02.

Adams, Z., R. Füss, and R. Gropp (2014), "Spillover Effects among Financial Institutions: A StateDependent Sensitivity Value-at-Risk (SDSVaR) Approach”, Journal of Financial and Quantitative Analysis, 49(3), 575-598.

Adrian, T., and M.K. Brunnermeier (2011), “CoVaR”, Working paper, Princeton University, September 15.

Amihud, Y. (2002), “Illiquidity and Stock Returns: Cross-Section and Time-Series Effects”, Journal of Financial Markets, 5, 31-56.

Barberis, N., and A. Shleifer (2000), “Style Investing”, NBER Working Paper No. 8039.

Barberis, N., and A. Shleifer (2003), "Style Investing”, Journal of Financial Economics, 68, 161-199.

Barberis, N., A. Shleifer, and J. Wurgler (2005), “Comovement”, Journal of Financial Economics, 75, 283-317.

Bartram, S., and G. Bodnar (2009), "No Place to Hide: The Global Crisis in Equity Markets in 2008/2009”, Journal of International Money and Finance, 28(8), 1246-1292.

Basak, S., and A. Pavlova (2014). “A Model of Financialization of Commodities”, Working paper, London Business School.

Bauwens, L., S. Laurent, and J.V.K. Rombouts (2006), "Multivariate GARCH Models: A Survey”, Journal of Applied Econometrics, 21(1), 79-109.

Bessembinder. H. (1992), "Systematic Risk, Hedging Pressure and Risk Premiums in Futures Markets”, Review of Financial Studies, 5(4), 637-667.

Bessembinder, H., and K. Chan (1992), “Time-varying Risk Premia and Forecastable Returns in Futures Markets”, Journal of Financial Economics, 32, 169-193.

Bollerslev, T. (1990), "Modeling the Coherence in Short-Run Nominal Exchange Rates: A Multivariate Generalized ARCH Model”, Review of Economics and Statistics, 72(3), 498-505.

Boyer, H.B. (2011), “Style-Related Comovement: Fundamentals or Labels?”, The Journal of Finance, 66, 307-332.

Boyson, N.M., C.W. Stahel, and R.M. Stulz (2010), ”Hedge Fund Contagion and Liquidity Shocks”, The Journal of Finance, 55(5), 1789-1816.

Brownlees, C.T., and R.F. Engle (2011), ”Volatility, Correlation and Tails for Systemic Risk Measurement”, Working paper, Stern School of Business, New York University.

Brunnermeier, M.K. (2008), “Deciphering the Liquidity and Credit Crunch 2007-2008”, Journal of Economic Perspectives, 23(1), 77-100.

Brunnermeier, M.K., and L.H. Pedersen (2009), "Market Liquidity and Funding Liquidity”, The Review of Financial Studies 22(6), 2201-2238.

Büyükşahin, B., M. Haigh, J. Harris, J. Overdahl, and M. Robe (2008), "Fundamentals, Trader Activity and Derivative Pricing”, EFA 2009 Bergen Meetings Paper, available at SSRN: http://papers.ssrn.com/sol3/papers.cfm?abstract_id=966692.

Büyükşahin, B., M. Haigh, and M. Robe (2010), “Commodities and Equities: Ever a Market of One?”, Journal of Alternative Investments 12, 76-95.

Büyükşahin, B., and J. Harris (2011), “Do speculators drive crude oil prices?”, The Energy Journal, 32(2), 167-202.

Büyükşahin, B., and M.A. Robe (2014), "Speculators, Commodities and Cross-Market Linkages", Journal of International Money and Finance, 42, 38-70.

Casey, T. (2011), “Financialization and the Future of the Neo-liberal Growth Model”, Political Studies Association Conference Proceedings. 
Cheng, I.-H., A. Kirilenko., and W. Xiong (2014), "Convective Risk Flows in Commodity Futures Markets“, Review of Finance, forthcoming.

Cheng, I.-H., and W. Xiong (2013), “The Financialization of Commodity Markets”, Working paper, Princeton university.

Cochrane, J.H., F.A. Longstaff, and P. Santa-Clara (2008), “Two Trees”, Review of Financial Studies, 21(1), 374-385.

Corvin, S.A., and P. Schultz (2012). "A Simple Way to Estimate Bid-Ask Spreads from Daily High and Low Prices”, The Journal of Finance, 67(2), 719-759.

Daskalaki, C., and G. Skiadopoulos (2011), "Should Investors Include Commodities in their Portfolios after all?”, Journal of Banking and Finance, 35(10), 2606-2626.

Davidson, J. (1994), “Stochastic Limit Theory”, Oxford University Press.

Domanski, D., and A. Heath (2007), "Financial Investors and Commodity Markets”, BIS Quarterly Review, March 2007.

Dusak, K. (1973), "Futures Trading and Investor Returns: An Investigation of Commodity Market Risk Premiums”, Journal of Political Economy, 81(6), 1387-1406.

Ederington, L., and J.H. Lee (2002). "Who trades futures and how: evidence from the heating oil market”, Journal of Business, 75, 353-373.

Engle, R.F., C.W.J. Granger, and D. Kraft (1984), “Combining Competing Forecasts of Inflation using a Bivariate ARCH Model”, Journal of Economic Dynamics and Control, 8(2), 151-165.

Erb, C.B., and C.R. Harvey (2006), "The Strategic and Tactical Value of Commodity Futures Markets”, Financial Analysts Journal, 62(2), 69-97.

Feldstein, M. (1999), “Self-Protection for Emerging Market Economies”, NBER working paper series No. 6907.

Füss, R., T. Glück, and J. Mutl (2012), “Spurious Dynamic Conditional Correlation”, Working paper, available at http://papers.ssrn.com/abstract=1963728.

Galeano, P., and D. Wied (2014), "Multiple Break Detection in the Correlation Structure of Random Variables”, Computational Statistics and Data Analysis, 76, 262-282.

Gorton, G.B., and K.G. Rouwenhorst (2006), "Facts and Fantasies about Commodity Futures”, Financial Analysts Journal, 62, 47-68.

Gorton, G.B., F. Hayashi, and K.G. Rouwenhorst (2013), “The Fundamentals of Commodity Futures Returns”, Review of Finance, 17(1), 35-105

Gulko, L. (2002), “Decoupling”, Journal of Portfolio Management, 28(3), 59-66.

Hanson, L.P., and R.J. Hodrick (1980), "Forward Exchange Rates as Optimal Predictors of Future Spot Rates: An Econometric Analysis”, Journal of Political Economy, 88(5), 829-853.

Henderson, B.J., N.D. Pearson, and L. Wang (2015), "New Evidence on the Financialization of Commodity Markets”, Review of Financial Studies, 28(5), 1287-1311.

Hicks, J. R. (1939), “Value and Capital”, Oxford University Press, Cambridge, UK

Hirshleifer, D. (1988), “Residual Risk, Trading Costs and Commodity Futures Risk Premia”, Review of Financial Studies, 1(2), 173-193.

Hong, H., and M. Yogo (2012), "What Does Futures Market Interest Tell us About the Macroeconomy and Asset Prices?”, Journal of Financial Economics, 105, 473-490.

Hsiao, C. (2004), “Analysis of Panel Data”, $2^{\text {nd }}$ e., Cambridge University Press.

Irwin, S.H., and D.R. Sanders (2011), "Index Funds, Financialization, and Commodity Futures Markets”, Applied Economic Perspectives and Policy, 33(1), 1-31.

Irwin, S.H., and D.R. Sanders (2012), "Testing the Masters Hypothesis in commodity futures markets”, Energy Economics, 34, 256-269. 
Jegadeesh, N., and S. Titman (2001), "Profitability of Momentum Strategies: An Evaluation of Alternative Explanations”, The Journal of Finance, 56, 699-720.

Jorion, P. (2006), "Value at Risk: The New Benchmark for Managing Financial Risk", $3^{\text {rd }}$ e., McGraw-Hill

Keynes, J. (1930), “A Treatise on Money”, Vol. 2, Macmillan, London.

Kocherginsky, M., X. He, and Y. Mu (2005), "Practical Confidence Intervals for Regression Quantiles”, Journal of Computational and Graphical Statistics, 14(1), 41-55.

Kroner, K.F., and V.K. Ng (1998), "Modeling Asymmetric Comovements of Asset Returns”, The Review of Financial Studies, 11(4), 817-844.

Lee, C., A. Shleifer, and R. Thaler (1991), "Investor Sentiment and the Closed-End Fund Puzzle”, The Journal of Finance, 46, 75-110.

Litzenberger, R., and K. Ramaswamy (1979), “The Effect of Personal Taxes and Dividends on Capital Asset Prices: Theory and Empirical Evidence”, Journal of Financial Economics, 7, 163-196.

Marshall, B., N. Nguyen, and N. Visaltanachoti (2013), ”Liquidity Commonality in Commodities”, Journal of Banking and Finance, 37(1),11-20.

Mou, Y. (2011), "Limits to Arbitrage and Commodity Index Investment: Front-Running the Goldman Roll”, Working Paper, Columbia University.

Nelson, D.B. (1991), “Conditional Heteroscedasticity in Asset Returns: A New Approach”, Econometrica, 59(2), 347-370.

Norrish, K. (2010), “Commodity Investor Audience Survey Results”, 6th Annual Commodity Investor Conference, Barcelona, Spain, March 4-5.

Sanders, D.W., and S.H. Irwin (2013), "Measuring Index Investment in Commodity Futures Markets", The Energy Journal, 34(3), 105-127.

Shleifer, A., and R. Vishny (2011), "Fire Sales in Finance and Macroeconomics", Journal of Economic Perspectives, 25(1), 29-48.

Stoll, H. and R. Whaley (2010), “Commodity index investing and commodity futures prices”, Journal of Applied Finance 1, 1-40.

Tang, K., and W. Xiong (2012), “Index Investment and Financialization of Commodities”, Financial Analysts Journal, 68(6), 54-74.

Tang, K., and H. Zhu (2015), “Commodities as Collateral”, MIT Sloan Working Paper.

Tse, Y., and A. Tsui (1999): “A Note on Diagnosting Multivariate Conditional Heteroscedasticity Models”, Journal of Time Series Analysis, 20(6), 679-691.

US Senate Permanent Subcommittee on Investigations (2009), "Excessive Speculation in the Wheat Market”, Committee on Homeland Security and Governmental Affairs, June 24.

Wahal, S., and M.D. Yavuz (2013), "Style Investing, Comovement and Return Predictability”, Journal of Financial Economics, 107(1), 136-154.

Wied, D., W. Krämer, and H. Dehling (2012), "Testing for a Change in Correlation at an Unknown Point in Time Using an Extended Functional Delta Method”, Econometric Theory, 28(3), 570589. 


\section{Panel A: Relative Performance of Commodities}

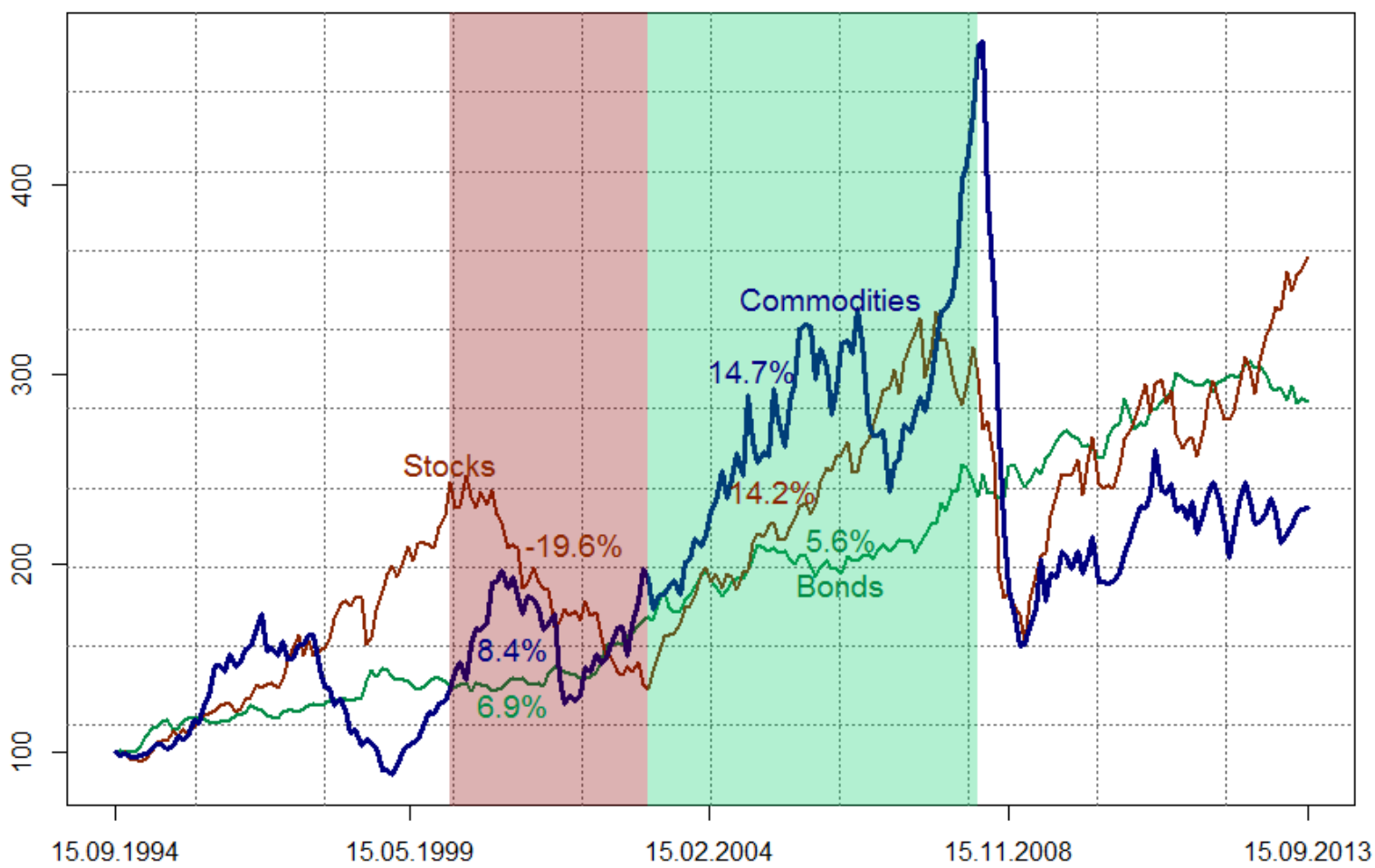

Panel B: Investments in Commodity Futures Increase
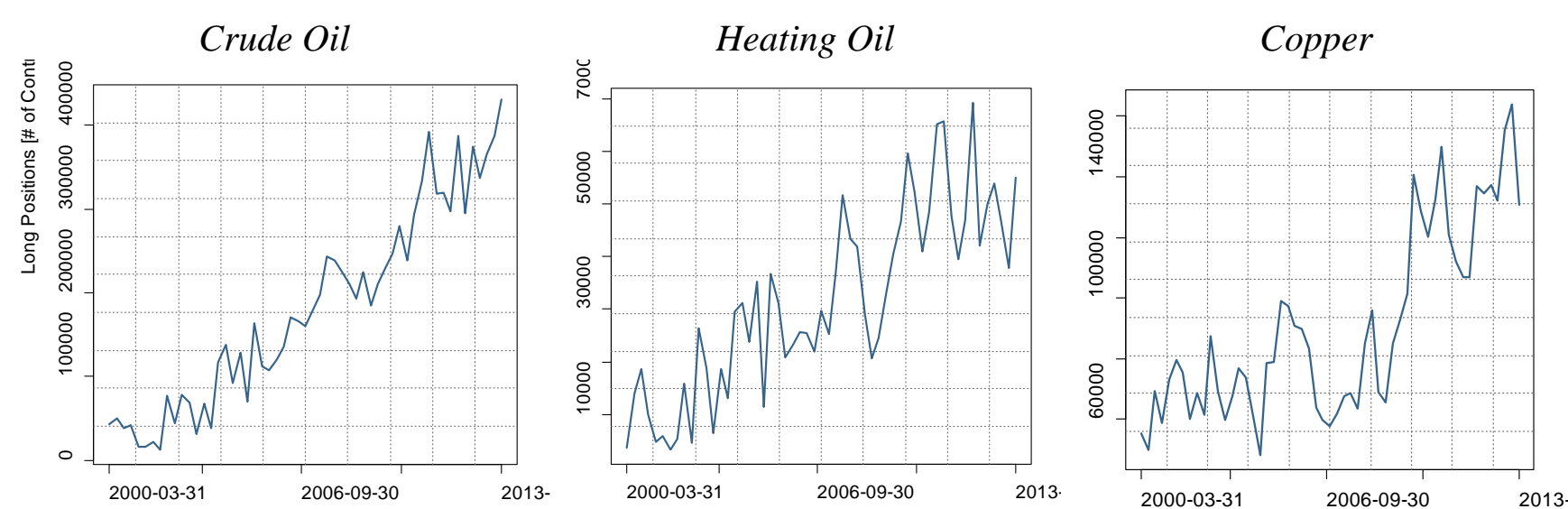

This figure shows the performance of commodities relative to stocks and bonds and the following increase in commodity futures long positions. Panel A shows the cumulative returns of the GSCI total return index, the MSCI World total return index, and the Bank of America Merrill Lynch total return index from 1994 to 2013. Panel B shows the number of noncommercial long positions in selected commodity futures since 2000. 

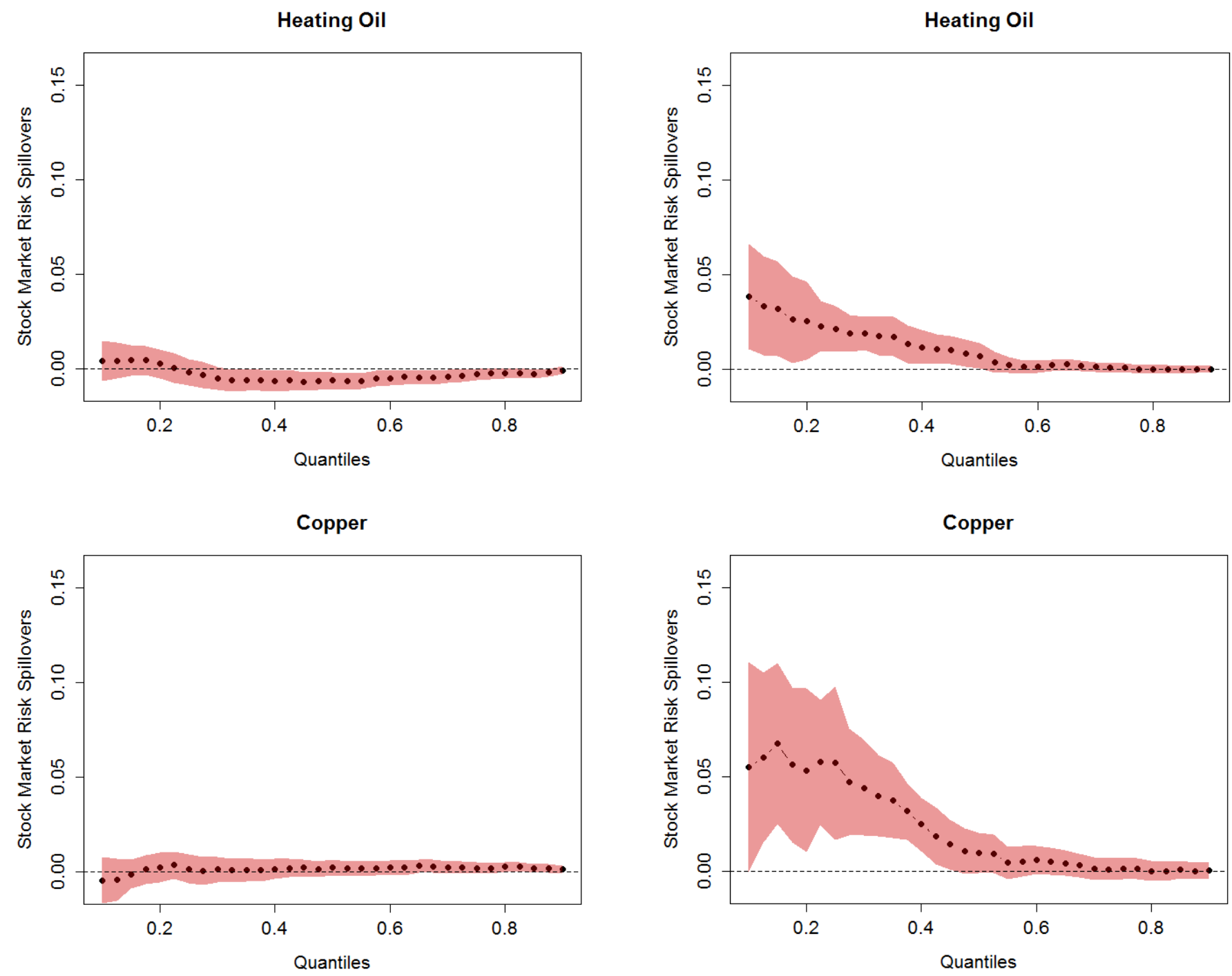

Crude Oil
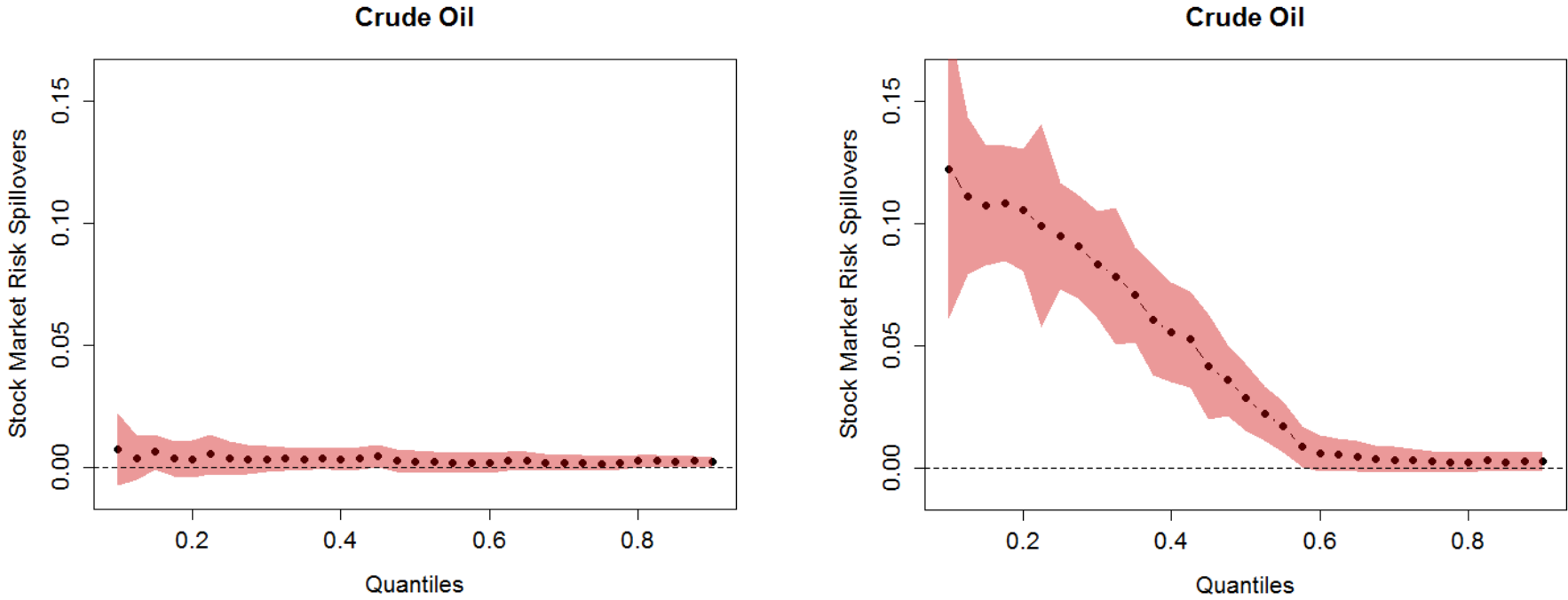

This figure shows the estimated risk spillover coefficients for heating oil, copper, and crude oil. Spillovers are nonexistent before September 2008 (sample period 1) but are predominant in the tails of the VaR distribution after the identified break in the correlation structure (sample period 2). 
Figure 3: The Impact of Risk Spillovers on the Variation of a Stock/Commodity Portfolio

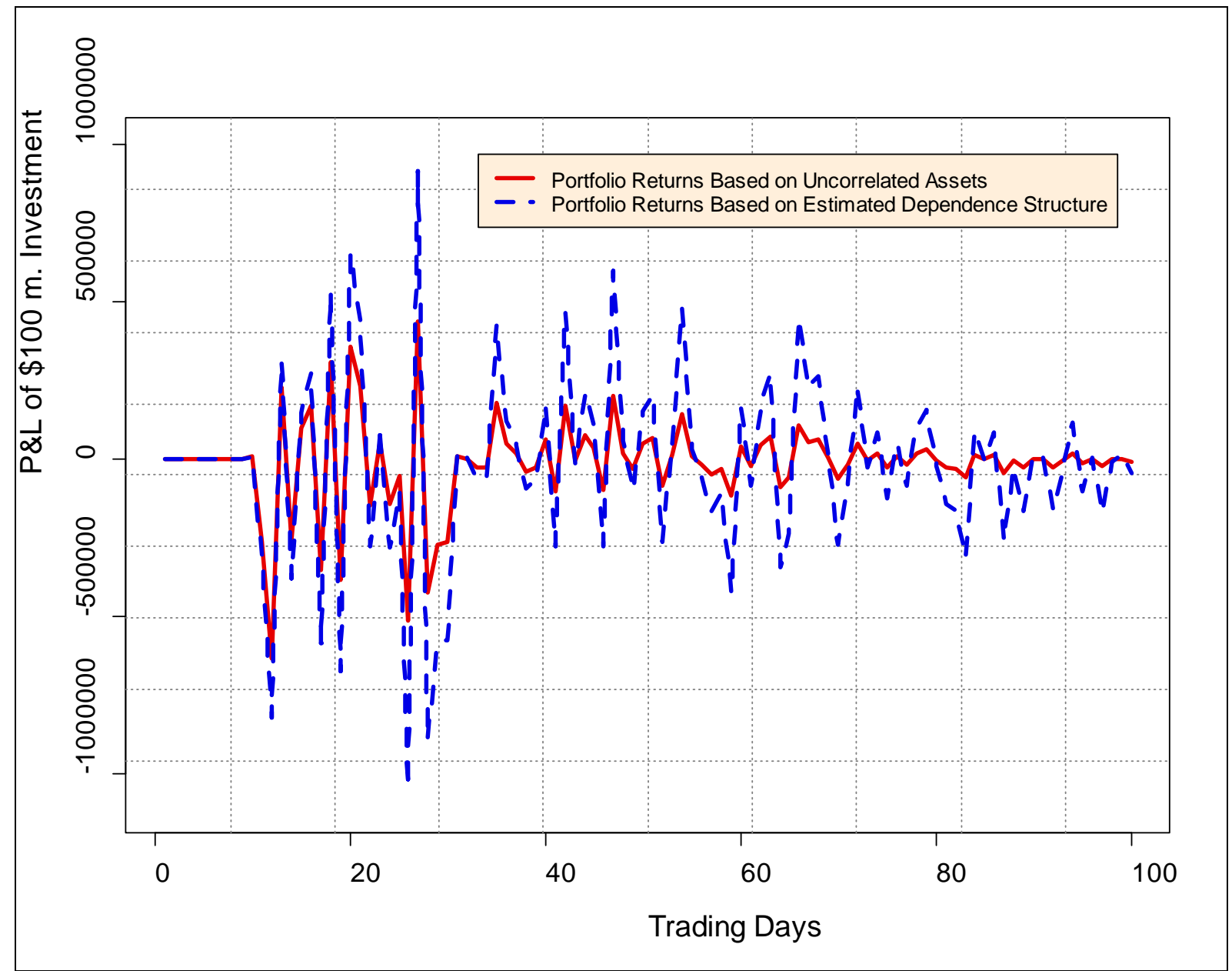

This figure compares the returns of two hypothetical portfolios experiencing a shock in one of it's constituents (the S\&P 500). The control portfolio (solid red line) is based on the traditional finding that stocks and commodities are uncorrelated. The treatment portfolio (dashed blue line) is based on the estimated dependence structure from Table 5 and therefore takes into account that a shock in the stock market also affects the risk in commodity markets. 
Figure 4: Dynamics in Risk Spillover Estimates
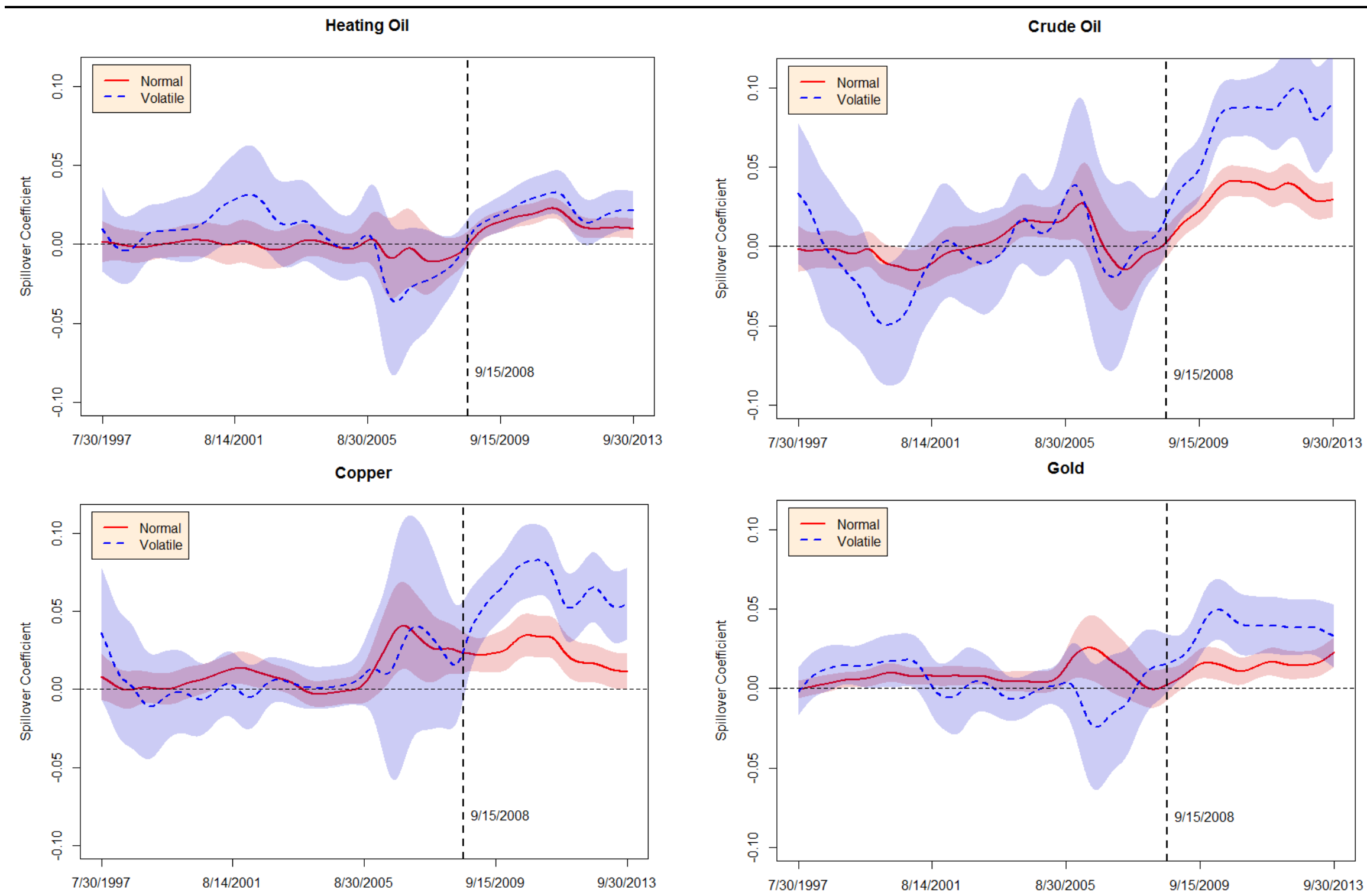

This figure shows the daily time series of estimated spillover coefficients according to Eq.(5). The coefficients are based on a three year rolling window to reduce the daily fluctuation that is typical for rolling window quantile regressions. The remaining short-term noise is eliminated with a HP filter. The red solid line shows the spillovers that are estimated to occur during normal market times. The blue dashed line shows the response to the same shocks when the commodity is trading in a highly volatile market. 
Figure 5: Expected vs Estimated Risk Spillovers for Crude Oil

\section{Panel A: Simulated and Actual Crude Oil VaR}

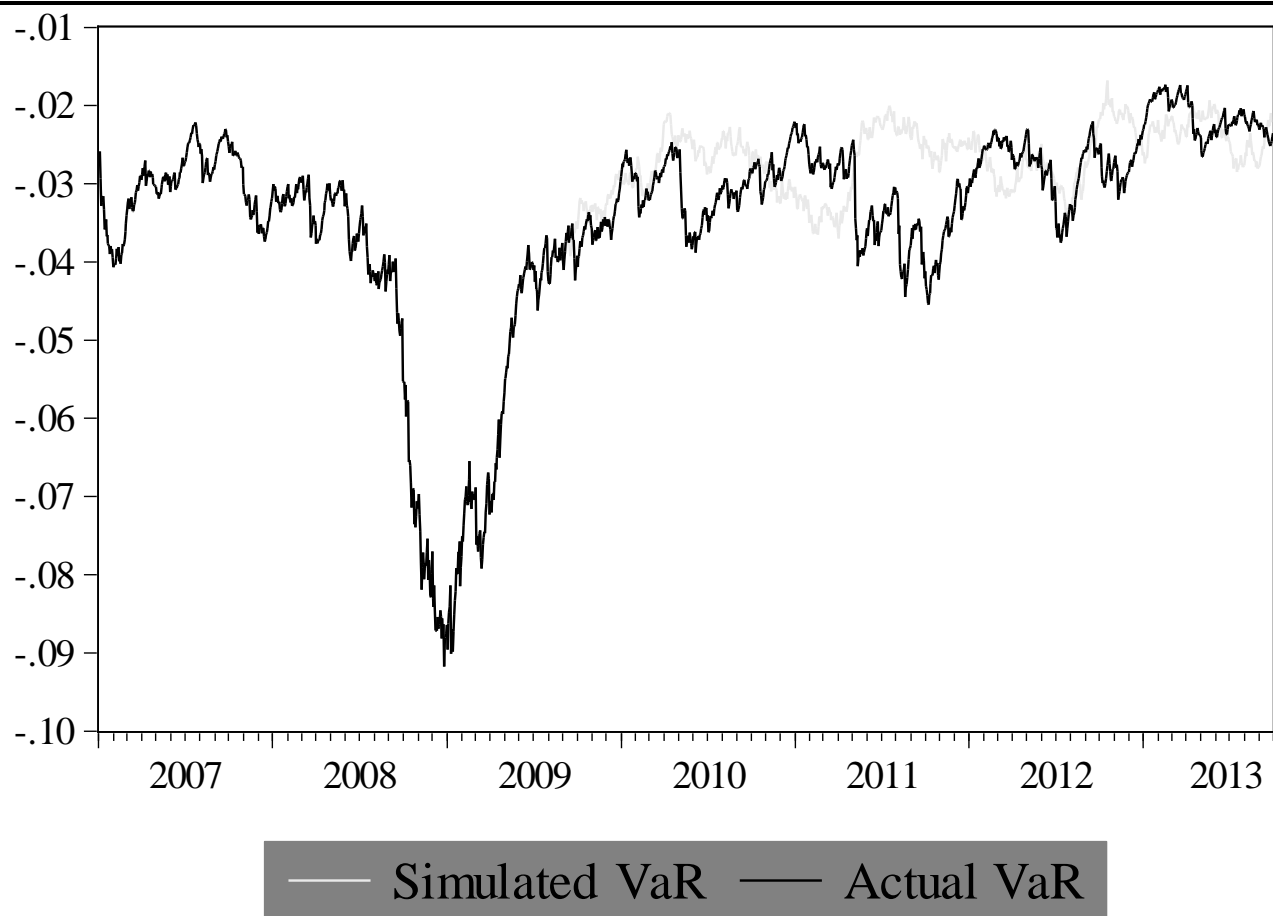

Panel B: Estimated Spillover and Expected Spillover

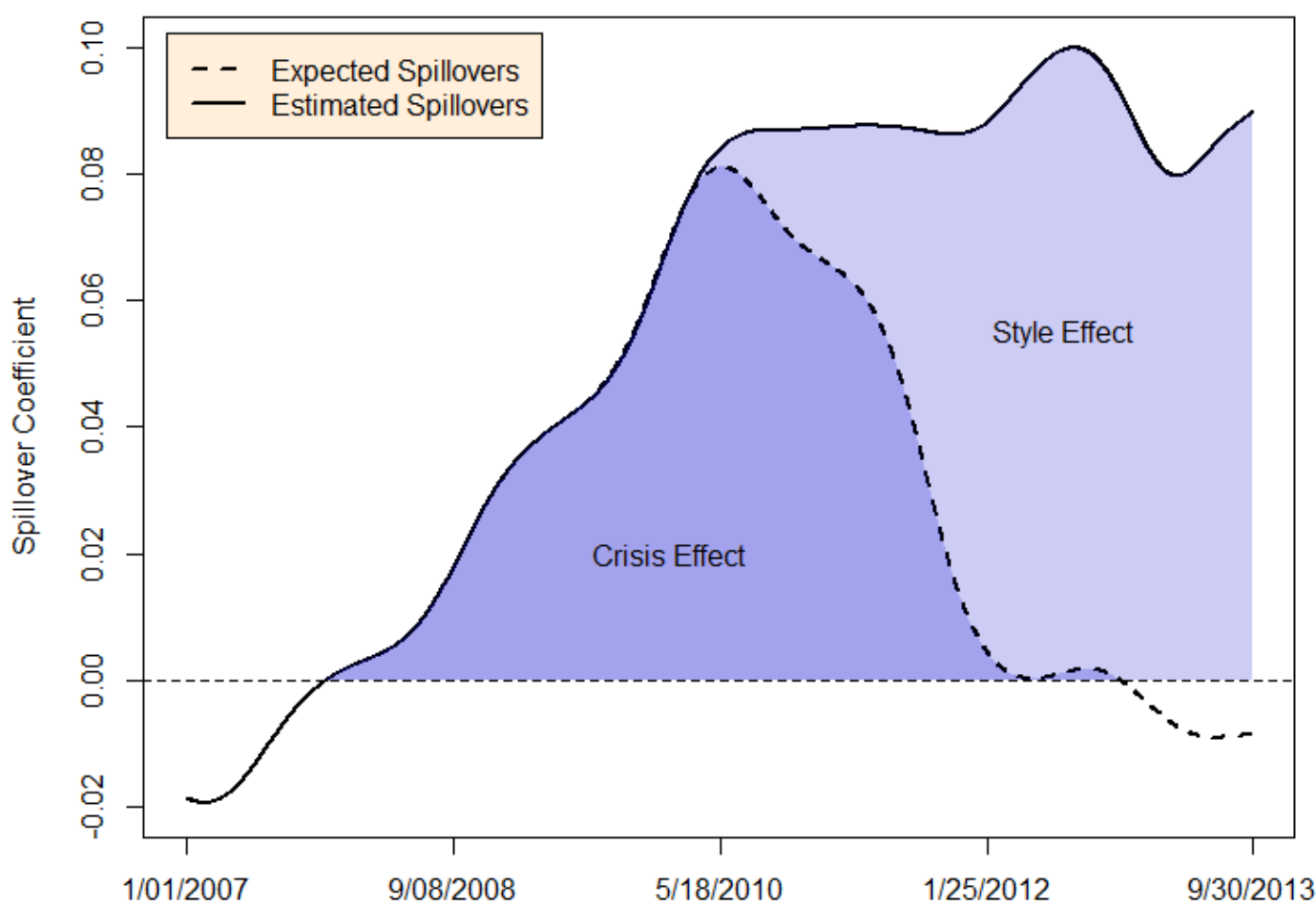

This figure shows the development of risk spillovers for crude oil estimated from a 750 day rolling window and compares this estimate with a hypothetical spillover that would be observed when the VaR of crude oil were to return to its pre-crisis behavior at the end of August 2009. The simulated crude oil VaR after August 2009 has the same mean, variance, and degree of autocorrelation as before the crisis but consists of random shocks. 
Figure 6: Performance of Commodity Index and Constituents

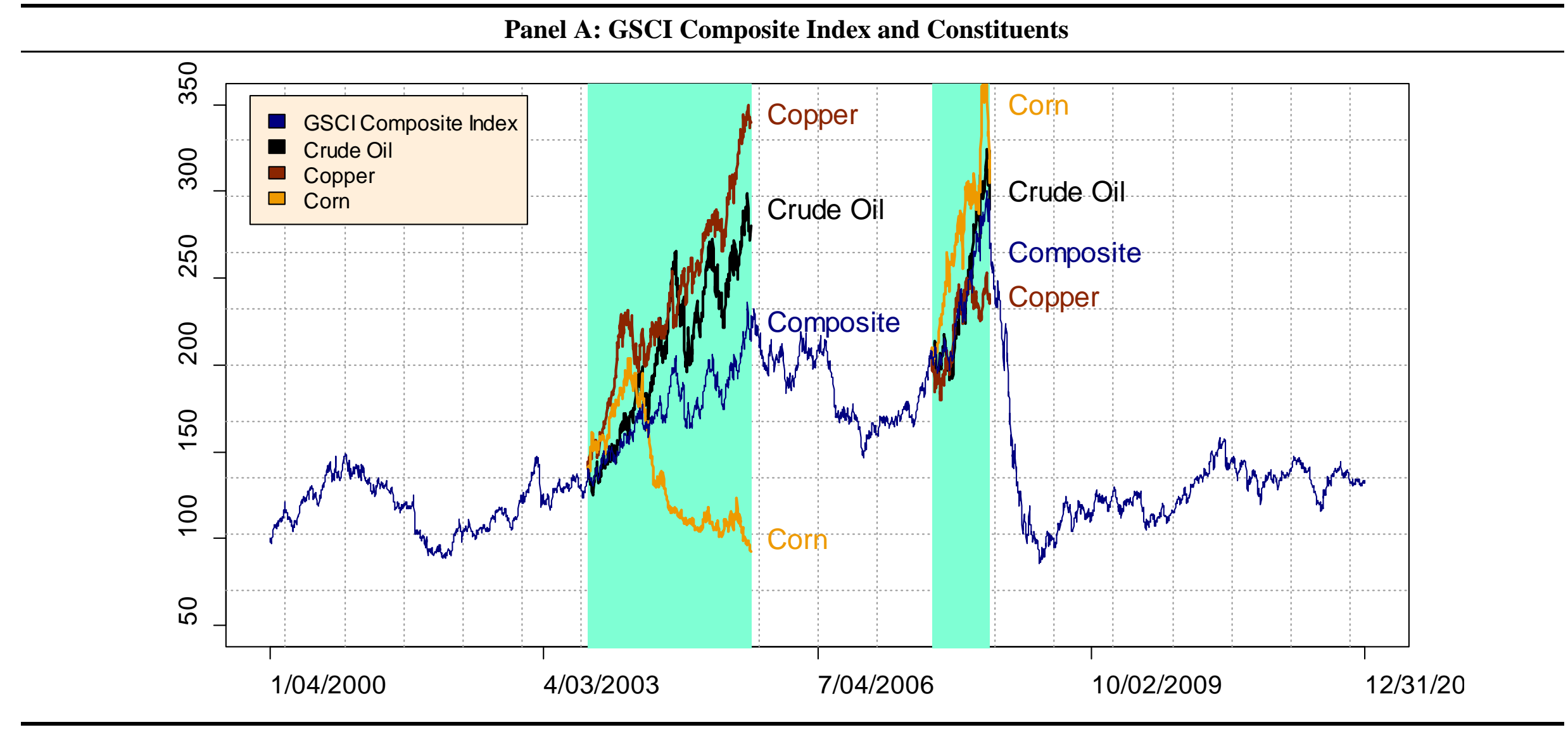

Panel B: Performance of Constituents relative to the Index

\begin{tabular}{ccccccccc}
\hline \multicolumn{7}{c}{ Sample Period 2003M10 - 2005M9 } \\
\hline Aluminum & Cattle & Copper & Corn & Crude Oil & Gold & Heating Oil & Wheat & Composite \\
\hline $20.4 \%$ & $-7.7 \%$ & $141.9 \%$ & $-34 \%$ & $99.5 \%$ & $15.1 \%$ & $113.7 \%$ & $-21.6 \%$ & $56.8 \%$ \\
\hline
\end{tabular}

Sample Period 2007M11 - 2008M7 


\begin{tabular}{ccccccccc}
\hline Aluminum & Cattle & Copper & Corn & Crude Oil & Gold & Heating Oil & Wheat & Composite \\
\hline $13.7 \%$ & $-10.3 \%$ & $14.7 \%$ & $47.1 \%$ & $39.6 \%$ & $13.5 \%$ & $48.5 \%$ & $-5.8 \%$ & $30 \%$ \\
\hline
\end{tabular}

This figure shows the performance of the S\&P GSCI composite index from 2000 to 2012. Over this 12 year time interval, there have been two periods during which the composite index was performing particularly well. The figure also shows the performance of selected commodities during these two periods relative to the index. 
Table 1: S\&P GSCI Constituent Weights for Selected Commodities

\begin{tabular}{|c|c|c|}
\hline & Index Weight & Subsector Weight \\
\hline \multicolumn{3}{|l|}{ Agricultural } \\
\hline Corn & 5.0 & 32.1 \\
\hline \multirow[t]{2}{*}{ Wheat } & 4.4 & 28.2 \\
\hline & & $\sum=60.3$ \\
\hline \multicolumn{3}{|l|}{ Energy } \\
\hline Crude Oil & 48.4 & 70.1 \\
\hline \multirow[t]{2}{*}{ Heating Oil } & 5.2 & 7.7 \\
\hline & & $\sum=77.8$ \\
\hline \multicolumn{3}{|l|}{ Base Metals } \\
\hline Copper & 3.3 & 47.8 \\
\hline \multirow[t]{2}{*}{ Aluminum } & 2.1 & 30.4 \\
\hline & & $\sum=78.2$ \\
\hline \multicolumn{3}{|c|}{ Precious Metals } \\
\hline Gold & 3.1 & 86.1 \\
\hline \multicolumn{3}{|l|}{ Livestock } \\
\hline Cattle & 3.5 & 70.0 \\
\hline$\sum$ & 79.0 & \\
\hline \multicolumn{3}{|c|}{$\begin{array}{l}\text { This table shows GSCI constituent weights as of December } 31,2012 \text {. The index } \\
\text { weights refer to the weight of a commodity in the GSCI composite index. The } \\
\text { subsector weights refer to the weights within a particular commodity subsector. For } \\
\text { example, the category precious metals consists of the two commodities gold and } \\
\text { silver. Although gold and silver play only a minor role in the overall composite index } \\
\text { with a weight of } 3.1 \% \text { for gold and } 0.5 \% \text { for silver, gold is the main component of the } \\
\text { precious metals category with a subsector weight of } 3.1 /(3.1+0.5)=86.1 \% \text {. The full lis } \\
\text { of index constituents and corresponding weights can be obtained from the index } \\
\text { provider's website: http://us.spindices.com/index-family/commodities/sp-gsci. }\end{array}$} \\
\hline
\end{tabular}


Table 2: Descriptive Statistics of Continuously Compounded Returns

\begin{tabular}{|c|c|c|c|c|c|c|c|c|c|}
\hline & S\&P 500 & Alu & Cattle & Copper & Corn & Crude Oil & Gold & Heat.Oil & Wheat \\
\hline \multicolumn{10}{|c|}{ Panel A: Summary Statistics } \\
\hline Mean & 0.025 & -0.017 & -0.011 & 0.028 & -0.026 & 0.023 & 0.013 & 0.02 & -0.04 \\
\hline Std.dev & 1.218 & 1.306 & 0.872 & 1.66 & 1.652 & 2.142 & 1.068 & 2.035 & 1.778 \\
\hline Auto.Cor & $-0.07^{* * *}$ & -0.02 & $0.027^{*}$ & $-0.042^{* * *}$ & $0.048^{* * *}$ & -0.015 & 0.005 & $-0.024^{*}$ & 0.003 \\
\hline \multicolumn{10}{|c|}{ Panel B: Sample Correlations } \\
\hline S\&P 500 & 1 & - & - & - & - & - & - & - & - \\
\hline Alu & $0.193^{* * *}$ & 1 & - & - & - & - & - & - & - \\
\hline Cattle & $0.099^{* * *}$ & $0.100^{* * *}$ & 1 & - & - & - & - & - & - \\
\hline Copper & $0.235^{* * *}$ & $0.683^{* * *}$ & $0.116^{* * *}$ & 1 & - & - & - & - & - \\
\hline Corn & $0.111^{* * *}$ & $0.179^{* * *}$ & $0.112^{* * * *}$ & $0.192^{* * *}$ & 1 & - & - & - & - \\
\hline Crude Oil & $0.173^{* * *}$ & $0.239^{* * *}$ & $0.120^{* * *}$ & $0.284^{* * *}$ & $0.213^{* * *}$ & 1 & - & - & - \\
\hline Gold & -0.015 & $0.269^{* * *}$ & $0.047^{* * *}$ & $0.306^{* * *}$ & $0.174^{* * *}$ & $0.229^{* * *}$ & 1 & - & - \\
\hline Heat.Oil & $0.141^{* * *}$ & $0.212^{* * *}$ & $0.093^{* * *}$ & $0.247^{* * *}$ & $0.191^{* * *}$ & $0.901^{* * *}$ & $0.213^{* * *}$ & 1 & - \\
\hline Wheat & $0.108^{* * *}$ & $0.165^{* * *}$ & $0.106^{* * * *}$ & $0.192^{* * *}$ & $0.635^{* * *}$ & $0.201^{* * *}$ & $0.161^{* * *}$ & $0.178^{* * *}$ & 1 \\
\hline
\end{tabular}

Panel A of this table shows means, standard deviations and first order autocorrelations of a sample of daily log returns. Panel B shows corresponding crosscorrelations. The sample period ranges from 09/15/1994 to 09/30/2013 (4968 obs.). 
Table 3: Wied, Krämer, and Dehling (2012) Test for Structural Changes in Correlation

\begin{tabular}{lcc}
\hline & Untransformed Returns & Standardized Returns \\
\hline Corn & 3.759 & 2.464 \\
Wheat & 3.718 & 3.057 \\
Crude Oil & 5.381 & 5.286 \\
Heating Oil & 5.088 & 5.097 \\
Copper & 5.488 & 4.732 \\
Aluminum & 4.928 & 4.597 \\
Gold & 2.359 & 2.812 \\
Cattle & 3.145 & 2.497 \\
\hline
\end{tabular}

This table shows the test statistic $Q_{T}$ as defined in Equation (3) and based on either the untransformed log returns (second column) or log returns standardized by their EGARCH(1,1) conditional volatilities. Under the null hypothesis of no change in correlation $Q_{T}$ converges in distribution to a Kolmogorov distribution. Critical values are: $10 \%: 1.22,5 \%: 1.36$, and 1\%: 1.63 . The sample period ranges from 09/15/1994 to 09/30/2013. 
Table 4: Correlation Change-Point Inference

\begin{tabular}{lcc}
\hline & Change-Points & $\Delta \hat{\rho}$ \\
\hline Corn & $09 / 25 / 2008$ & 0.224 \\
\hline Wheat & $09 / 22 / 2008$ & 0.255 \\
\hline Crude Oil & $09 / 19 / 2008$ & 0.526 \\
\hline Heating Oil & $08 / 29 / 2008$ & 0.512 \\
Copper & $06 / 24 / 1999$ & 0.133 \\
& $08 / 29 / 2008$ & 0.273 \\
Aluminum & $04 / 11 / 2000$ & 0.185 \\
& $03 / 01 / 2004$ & -0.048 \\
& $11 / 21 / 2007$ & -0.232 \\
& $09 / 05 / 2008$ & 0.451 \\
\hline Gold & $10 / 15 / 2008$ & 0.193 \\
\hline Cattle & $09 / 17 / 2008$ & 0.234 \\
\hline
\end{tabular}

This table shows the correlation change-points estimated with the algorithm of Galeano and Wied (2014). The null hypothesis of constant correlations is rejected if the Wied, Krämer, and Dehling (2012) test statistic exceeds the critical value at the 1 percent significance level. We also report $\Delta \hat{\rho}$ which is the change in sample correlation between two consecutive subsamples determined by the change-points. For example, $\Delta \hat{\rho}$ for corn is given by the correlation of the subsample ranging from 09/26/08 to 09/30/2013 minus the correlation of the subsample ranging from 09/16/1994 to 09/25/2008. 
Table 5: Risk Spillovers from Stocks to Commodities

\begin{tabular}{|c|c|c|c|c|c|c|c|c|}
\hline \multicolumn{9}{|c|}{ Panel A: Sample Period before Lehman Bankruptcy: 9/15/1994 - 9/15/2008 } \\
\hline & Corn & Wheat & Crude & Heating & Copper & Alu & Gold & Cattle \\
\hline & \multicolumn{8}{|c|}{ Normal Period: $50 \%$ Quantile } \\
\hline Spillover & 0.0022 & 0.0015 & 0.0024 & $-0.0061^{*}$ & 0.0025 & -0.0003 & 0.0025 & -0.0006 \\
\hline Lag & $0.9750^{*}$ & $0.9758^{*}$ & $0.9785^{*}$ & $0.9569^{*}$ & $0.9881^{*}$ & $0.9821^{*}$ & $0.9829^{*}$ & $0.9767^{*}$ \\
\hline Commodities & - & - & $0.0524^{*}$ & $0.0688^{*}$ & - & - & - & - \\
\hline \multirow[t]{2}{*}{ Emerg. Mkt. } & - & - & - & -0.0009 & 0.0027 & - & - & - \\
\hline & \multicolumn{8}{|c|}{ Volatile Period: $12.5 \%$ Quantile } \\
\hline Spillover & -0.0026 & 0.0092 & 0.004 & 0.0044 & -0.0039 & -0.0078 & -0.0034 & -0.0024 \\
\hline Lag & $1.0404^{*}$ & $1.0349^{*}$ & $1.0064^{*}$ & $0.9487^{*}$ & $1.0264^{*}$ & $1.0115^{*}$ & $1.029^{*}$ & $1.0153^{*}$ \\
\hline Commodities & - & - & $0.0501^{*}$ & $0.1295^{*}$ & - & - & $0.0122^{*}$ & - \\
\hline Emerg. Mkt. & - & - & - & $-0.0109^{*}$ & 0.0045 & $0.0124^{*}$ & $0.0116^{*}$ & - \\
\hline \multicolumn{9}{|c|}{ Panel B: Sample Period After Lehman Bankruptcy: 9/15/2008 - 9/30/2013 } \\
\hline & Corn & Wheat & Crude & Heating & Copper & Alu & Gold & Cattle \\
\hline & \multicolumn{8}{|c|}{ Normal Period: $50 \%$ Quantile } \\
\hline Spillover & 0.0039 & 0.0022 & $0.0401^{*}$ & $0.0072^{*}$ & 0.0071 & 0.0011 & $0.0097^{*}$ & $0.0025^{*}$ \\
\hline Lag & $0.9667^{*}$ & $0.9792^{*}$ & $0.9399^{*}$ & $0.9682^{*}$ & $0.9483^{*}$ & $0.9797^{*}$ & $0.968^{*}$ & $0.9753^{*}$ \\
\hline Commodities & - & - & $0.0725^{*}$ & $0.0237^{*}$ & $0.0136^{*}$ & 0.0057 & - & - \\
\hline Emerg. Mkt. & - & - & -0.0131 & -0.0030 & $0.0185^{*}$ & - & - & - \\
\hline
\end{tabular}


Volatile Period: $12.5 \%$ Quantile

\begin{tabular}{|c|c|c|c|c|c|c|c|c|}
\hline \multirow[b]{2}{*}{ Spillover } & \multicolumn{8}{|c|}{ Volatile Period: 12.5\% Quantile } \\
\hline & $0.0290^{*}$ & -0.0036 & $0.1428^{*}$ & $0.0336^{*}$ & $0.0602^{*}$ & 0.0073 & $0.0173^{*}$ & $0.0181^{*}$ \\
\hline Lag & $1.0227^{*}$ & $1.0211^{*}$ & $0.8886^{*}$ & $0.9105^{*}$ & $0.9221^{*}$ & $0.986^{*}$ & $0.9875^{*}$ & $0.9713^{*}$ \\
\hline Commodities & - & - & $0.2756^{*}$ & $0.1347^{*}$ & - & $0.0188^{*}$ & - & - \\
\hline Emerg. Mkt. & - & - & -0.0444 & $-0.0309^{*}$ & $0.0933^{*}$ & - & - & - \\
\hline
\end{tabular}

This table shows the risk spillover coefficients $\beta_{1, \theta}$ from Equation (5) before, and after the identified break in the correlation structure between stocks and commodities. Within

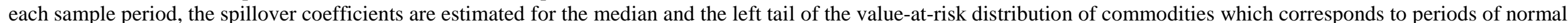

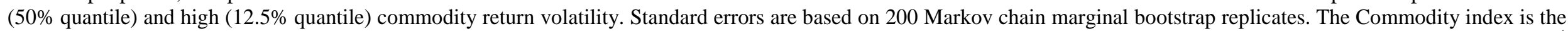
GSCI S\&P Composite excess return index excluding the commodity that is on the left hand side of the equation. Emerg.Mkt is the MSCI emerging market equity index. indicates statistical significance at the $5 \%$ level or higher. 
Table 6: The Impact of Liquidity and Past Performance on Risk Spillovers

\begin{tabular}{|c|c|c|c|c|c|}
\hline Model & & I & II & III & IV \\
\hline \multirow{2}{*}{ Open Interest $_{i, t}$} & Normal & $\begin{array}{l}0.001 \\
(0.35)\end{array}$ & - & - & $\begin{array}{l}-0.012 \\
(-3.86)\end{array}$ \\
\hline & Volatile & $\begin{array}{l}0.026 \\
(3.23) \\
\end{array}$ & - & - & $\begin{array}{r}0.004 \\
(0.52) \\
\end{array}$ \\
\hline \multirow{2}{*}{ Amihud $_{i, t}$} & Normal & - & $\begin{array}{l}0.003 \\
(2.13)\end{array}$ & - & - \\
\hline & Volatile & - & $\begin{array}{l}-0.007 \\
(-1.72) \\
\end{array}$ & - & - \\
\hline \multirow{2}{*}{ 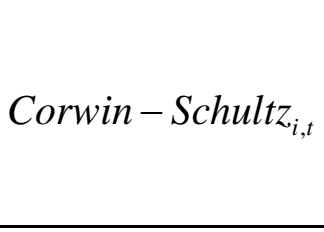 } & Normal & - & - & $\begin{array}{l}-0.001 \\
(-0.37)\end{array}$ & - \\
\hline & Volatile & - & - & $\begin{array}{l}-0.007 \\
(-2.62) \\
\end{array}$ & - \\
\hline \multirow{2}{*}{ CIT Net Long $_{i, t}$} & Normal & $\begin{array}{l}0.009 \\
(2.45)\end{array}$ & $\begin{array}{l}0.010 \\
(5.26)\end{array}$ & $\begin{array}{l}0.009 \\
(4.16)\end{array}$ & $\begin{array}{l}0.009 \\
(2.93)\end{array}$ \\
\hline & Volatile & $\begin{array}{l}0.022 \\
(3.26) \\
\end{array}$ & $\begin{array}{c}0.027 \\
(10.45) \\
\end{array}$ & $\begin{array}{l}0.023 \\
(6.82) \\
\end{array}$ & $\begin{array}{l}0.020 \\
(2.97) \\
\end{array}$ \\
\hline \multirow{2}{*}{ Performance $_{i, t-3}$} & Normal & - & - & - & $\begin{array}{c}0.002 \\
(1.58)\end{array}$ \\
\hline & Volatile & - & - & - & $\begin{array}{l}0.003 \\
(1.27) \\
\end{array}$ \\
\hline \multirow{2}{*}{ Performance $_{i, t-4}$} & Normal & - & - & - & $\begin{array}{l}0.002 \\
(2.64)\end{array}$ \\
\hline & Volatile & - & - & - & $\begin{array}{l}0.006 \\
(2.60) \\
\end{array}$ \\
\hline Adj. $R^{2}$ & & 0.24 & 0.24 & 0.27 & 0.19 \\
\hline
\end{tabular}

This table shows different model specifications for explaining the variation in risk spillovers. The dependent variable is defined as the daily spillover coefficient from Equation (5) estimated in a three-year rolling window. The timeseries dimension is 21 quarters (2008Q3 - 2013Q3). The cross-sectional dimension is 4 commodities. All coefficients show the response to a one standard deviation increase. For instance, the coefficient for open interest in the first model specification (0.026) indicates that risk spillovers increase by 0.026 in response to a one standard deviation rise in liquidity (here, a one standard deviation increase corresponds to 27,534 additional futures contracts held by buyers and sellers). The $t$-statistics in parenthesis are based on Hanson and Hodrick (1980) standard errors. Amihud ${ }_{i, t}$ is the Amihud (2002) illiquidity measure Amihud ${ }_{i, t}=1 / D_{i, t} \sum_{t=1}^{D_{i, 1}}\left|R_{i, t}\right| /$ Volume $_{i, t}$. The Corvin and Schultz (2012) illiquidity measure is Corwin-Schultz $=\frac{2\left(e^{\alpha}-1\right)}{1+e^{\alpha}}$ with $\alpha=\frac{\sqrt{2 \beta}-\sqrt{\beta}}{3-2 \sqrt{2}}-\sqrt{\frac{\gamma}{3-2 \sqrt{2}}}, \beta=E\left\{\sum_{j=0}^{2}\left[\ln \left(\frac{H_{t+j}^{o}}{L_{t+j}^{o}}\right)\right]\right\}, \quad \gamma=\left[\ln \left(\frac{H_{t, t+1}^{o}}{L_{t, t+1}^{o}}\right)\right]^{2}$, and $H_{t}^{o}, L_{t}^{o}$ denoting daily high and low commodity prices, respectively. Both illiquidity measures are computed from daily data and aggregated to quarterly frequency. All regressions include commodity fixed effects. The adjusted $R$-squared measure indicates the goodness of fit from the volatile model. 